University of Rhode Island

DigitalCommons@URI

Open Access Master's Theses

1988

\title{
The Effect of Goal-Attainment and Perceived Athletic Competence on Global Self-Esteem in High School Swimmers
}

Kevin Scott Salisbury

University of Rhode Island

Follow this and additional works at: https://digitalcommons.uri.edu/theses

\section{Recommended Citation}

Salisbury, Kevin Scott, "The Effect of Goal-Attainment and Perceived Athletic Competence on Global SelfEsteem in High School Swimmers" (1988). Open Access Master's Theses. Paper 1714.

https://digitalcommons.uri.edu/theses/1714

This Thesis is brought to you for free and open access by DigitalCommons@URI. It has been accepted for inclusion in Open Access Master's Theses by an authorized administrator of DigitalCommons@URI. For more information, please contact digitalcommons-group@uri.edu. 


\author{
THE EFFECT OF GOAL-ATTAINMENT AND \\ PERCEIVED ATHLETIC COMPETENCE ON \\ GLOBAL SELF-ESTEEM IN \\ HIGH SCHOOL SWIMMERS \\ B Y \\ KEVIN SCOTT SALISBURY
}

\title{
A THESIS SUBMITTED IN PARTIAL FULLFILLMENT OF THE REQUIREMENTS FOR THE DEGREE OF MASTER OF SCIENCE IN PHYSICAL EDUCATION
}


Abstract

The purpose of this study was to examine the effect of goal attainment and two levels of athletic competence self-perceptions on global self-esteem. A second purpose was to test the applicability of a model (Sonstroem \& Morgan, in preparation) developed for tracing the manner in which fitness achievement may impact on general self-esteem. The model was revised to include goal attainment and self-evaluations of specific sport skills in an athletic achievement setting.

The sample consisited of 93 male high school varsity swimmers who had their parents sign an informed consent form and then completed the following inventories three times: Rosenberg's Self-Esteem Scale(SES) (1965), a modified Estimation Scale (EST)(Sonstroem, 1974) and Social Desirability Scale (SD) (Jackson, 1984), a study developed Personal Performance Goals Inventory (PPGI), and a study developed Self-Perceptions of Swimming Skills Inventory (SPSSI).

Specific hypotheses tested were: (1) The Test 1 scores of SPSSI and Estimation will be positively and significantly related, (2) Test 1 relationships between SPSSI and Estimation scores will be larger than relationships between SPSSI and SES scores, (3) The Test 1 scores of Estimation and SES will be positively and significantly related, (4) Goal attainment at mid-season is positively and significantly related to changes in SPSSI and Estimation scores at mid-season, (5) Goal attainment at mid-season is more highly related to changes in SPSSI scores than to changes in Estimation scores, (6) Changes in SPSSI scores at mid-season are positively and significantly related to changes in Estimation scores at mid-season, (7) Changes in Estimation scores at mid-season are positively and significantly related to changes in SES scores at mid-season, (8) Changes in SES scores at mid-season are more highly related to 
changes in Estimation scores at mid-season than to changes in SPSSI scores at mid-season, (9) Goal attainment at post-season is positively and significantly related to changes in SPSSI and Estimation scores from mid-season to post-season, (10) Goal attainment at post-season is more highly related to changes from mid-season to post-season in SPSSI as compared to Estimation scores, (11) Changes in SPSSI scores from mid to post-season are positively and significantly related to changes in Estimation scores from mid to post-season,(12) Changes in Estimation and SES scores from mid-season to post-season are positively and significantly related, and (13) Changes in SES scores from mid-season to post-season are more highly related to changes in Estimation as compared to changes in SPSSI scores over the same time period. Within the present study, the results obtained supported the following hypotheses: Hypotheses 1, 2, 3, 6, 11, 12, and 13. Additional analyses showed that goal attainment was positively and significantly related to swimming improvement from Test 1 to Test 2. Goal attainment was unrelated to self-esteem, self-evaluations of physical ability, and self-perceptions of swimming skills throughout the study.

The revised model was supported except for the relationship of goal attainment to the rest of the study variables. Additional research is recommended with this model which incorporates a goal setting training program for educating athletes on goal setting. Also the author recommends attempting to replicate the present study with different populations such as females, elite swimmers (Olympians), and possibly other athletes from other sports. 


\section{ACKNOWLEDGEMENTS}

The author would like to express his sincere appreciation to Dr. Robert J. Sonstroem, whose unending support and professional expertise was above and beyond the call of duty.

Special thanks are also extended to Dr. Thomas Manfredi and Dr. Thomas Gunning for their valuable recommendations. Sincere thanks also goes to my wife Lisa, whose patience and guidance throughout this research was invaluable. Thanks goes out to my Mom and Dad for their professional suggestions.

Finally, the author wishes to thank Roger Peck for his computer consulting, the RI Interscholastic League Swim Coaches, and especially the high school swimmers of the State of Rhode Island for serving as subjects in this study. 
Abstract

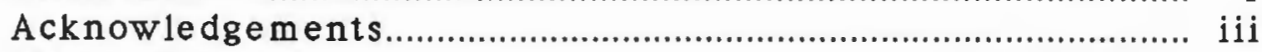

Table of Contents.......................................................................... iv

List of Tables.............................................................................

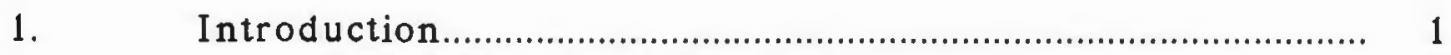

Statement of the Problem.................................................. 3

Specific Hypotheses....................................................... 5

Significance of the Study .................................................. 7

Definitions of Terms.......................................................... 9

Limitations of the Study..................................................... 10

2. Review of the Literature........................................................ 11

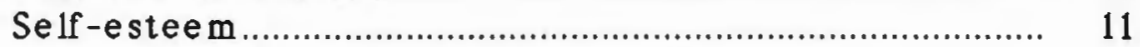

Proposed model for measuring self-esteem................... 14

Estimation Scale and the measurement of Narrow Traits 14

Self-perceptions of Swimming Skills............................... 16

Goal Setting/ Goal Attainment........................................... 18

3. Procedure

Selection of Subjects................................................. 21

Study Design................................................................... 21

Instruments Employed................................................... 23

Rosenberg Self-Esteem Scale........................................... 23

Estimation Scale............................................................... 24

Social Desirability Scale.................................................... 24

Self-perceptions of Swimming Skills Inventory............. 25

Personal Performance Goals Inventory........................... 25

Calculation of Study Variables............................................ 26

Statistical Analysis of Data............................................... 28

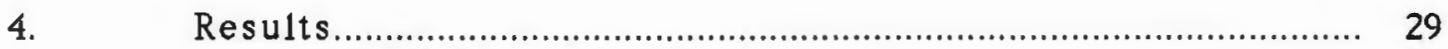

Descriptive Statistics........................................................ 29

Test of Hypotheses............................................................... 33

Summary of Hypotheses Testing....................................... 41

Discussion......................................................................... 43

Practical Implications ....................................................... 48

Recommendations for Future Research........................... 49

Conclusions................................................................... 50 
Table of Contents (continued)

Chapter

Page

References........................................................................................ 51

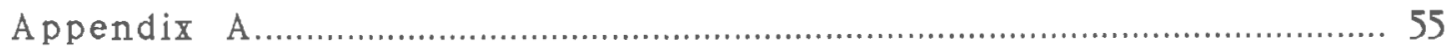

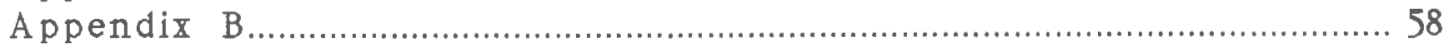

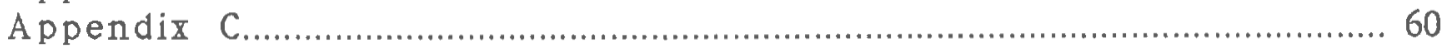

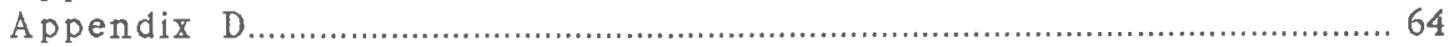

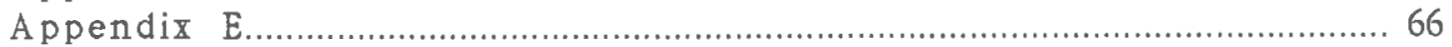

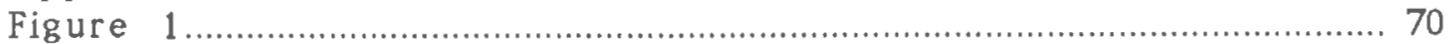

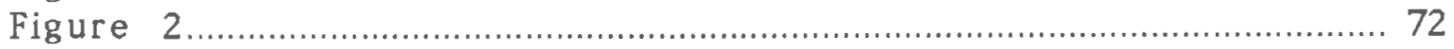




\section{List of Tables}

Table

Page

1 Means and Tests for Change -- Swim Times

Means and Tests for Change -- Self-perceptions

3 Relationships Among Self-perception Variables and Previous Performance

Correlation Matrix of Study Variables (Test 2 - Test 1)

36

5

Correlation Matrix of Study Variables (Test 3 - Test 2)

40

6

Summary of Hypotheses Testing

42

Static Relationships Between Model Variables Over the Course of A Season 


\section{CHAPTER I}

\section{Introduction}

The effects of exercise on global self-esteem has been of interest to sport psychologists and researchers for a long period of time. Self-esteem has been related to participation in extracurricular activities(Rosenberg, 1965), to possession of social skills(Coopersmith, 1967), academic achievement

(Felker,1974) and to leadership status(Rosenberg, 1965). Investigators believe the study of specific situations in sport could provide results on how self-esteem can be increased through athletic participation.

A review of 16 articles (Sonstroem, 1984) concluded that participation in physical exercise programs was associated with improved self-esteem.

Although the studies failed to control for response distortion and expectancies, improved self-esteem was present with enhanced physical fitness hypothesized as the causal agent. Although previous research tends to offer credibility to the exercise participation/self-esteem relationship, the effect of goal attainment and perceptions of athletic competence on self-esteem are absent in the research.

Sonstroem and Morgan have developed a model (Figure 1) (Sonstroem \& Morgan, in preparation) to examine the mechanisms of self-esteem change through exercise. The model hypothesizes that molecular level changes will have an effect on the more general variable such as global self-esteem. While the model incorporates the seven postulates of the Shavelson, Hubner, \& Stanton model (1976), it is hierarchially arranged vertically with physical self-efficacy at the bottom and global self-esteem at the top. The lower elements (self-efficacy) along the hierarchy are believed to be components of change for the upper elements (global self-esteem) in the model. Another component of the model that Harter (1982) has designated as one of three 
specific domains of global self-esteem is physical competence. Physical competence is referred to by Sonstroem \& Morgan (in preparation) as evaluations regarding ability at vigorous exercise and sport activities in general. As the model contains many self-agents of self-esteem change it does not include non-self agents such as goal-attainment, feedback, and social reinforcement.

Insert Figure 1 about here

Time is represented on the horizontal dimension in Figure 1 and contains at least two data points of testing, the initial test through to the nth test. These testing points are separated by the intervention of the exercise programs. The model therefore(right half of Figure 1) attempts to trace the manner in which lower elements effect changes in upper elements and vice versa. The time allotted between testings is fairly flexible although Sonstroem and Morgan(1986) have recommended a period of four months when physical fitness is hypothesized to interact with other components in changing global self-esteem.

This model to date has not been tested. The present study has utilized a modified version of the model with the sport of swimming.

Although Sonstroem and Morgan's proposed model utilizes measurable narrow components such as physical self-efficacy and physical competence, there has been no research done on other lower level components such as goal attainment and specific sport skills in the sport context. Goal setting has been used quite extensively in business settings (Locke, et al., 1981) but rarely used 
in sport research. The effect of an athlete's perception of specific sport skills on other self variables is another area where little research has been done.

More research is needed on these narrow or lower level elements and how they effect the athletes' cognitions, competence, and self-esteem. The present study has attempted to lend support to these narrow variables and to show how they may effect other variables in athletes.

The modified model for the present study (Figure 2) examined the manner in which self-estee $m$ is hypothesized to change. It is based on the premise that global self-esteem can be separated into multiple components of self-conception (Rosenberg, 1979). These components are hierarchically ordered on a dimension of generality after the model proposed by Shavelson, et. al. (1976). At lower levels (i.e., self-perceptions of swimming skills) self-conception is more situation specific and less stable than at higher levels. (i.e., global self-esteem and Estimation). Changes in skill were presumed to influence these congruent and more molecular self-perceptions. Changes in these specific self-perceptions should result in additional self-perception change at higher levels of generality.

Self-esteem was measured by the Rosenberg Self-Esteem Scale (Rosenberg, 1965); athletic competence was measured by a modified Estimation Scale from the PEAS (Sonstroem, 1978), and self-perceptions of swimming skills and goal attainment was measured by two study developed inventories: Self-Perceptions of Swimming Skills Inventory (SPSSI) and the Personal Performance Goals Inventory (PPGI), respectively.

\section{Statement of the Problem}

The purpose of this research was to examine the effect of goal attainment and two levels of self-perceptions of athletic competence on global 
self-esteem. Goal attainment was measured by the study developed Personal Performance Goals Inventory (Appendix A). Two levels of self-perceptions of athletic competence were ordered on a continuum of specificity-generality. The lower, more situation-specific level assessed perceptions of common swimming skills by means of a study-developed Self-Perceptions of Swimming Skills Inventory (SPSSI)(Appendix D). A modified Estimation scale from the Physical Estimation and Attraction Scales (PEAS) (Sonstroem, 1974) assessed general feelings of athletic competence (Appendix C, Section II). Global self-esteem was measured by the Rosenberg Self-Esteem Scale (SES) (Rosenberg, 1965) (Appendix B).

Ninety-three male secondary school swimmers competing in the Rhode Island Interscholastic League were administered the goals inventory, the SPSSI, the Estimation Scale, and the SES in November, before the first swimming competition, in January at the mid-point of the season, and in March at the season's close. The present design and variables permitted a test of the applicability of a model (Sonstroem \& Morgan, in preparation) developed for tracing the manner in which fitness achievement may impact on general self-esteem. Briefly, the model hypothesizes that relationships between self-perceptions of competence at adjacent levels of generality will be greater than relationships between variables more remotely removed along the generality continuum. Additionally, changes over time in the more molecular levels of self-perception will influence changes in global self-esteem. The model, revised to include goal attainment in an athletic achievement setting, is diagrammed in Figure 2. 
Insert Figure 2 About Here

The present design permitted analyses of static relationships (i.e., variable relationships at Test 1) as well as developmental relationships (i.e., relationships among changes in variables over time).

The specific hypotheses of this study were:

\section{HYPOTHESIS 1}

The Test 1 scores of SPSSI and Estimation will be positively and significantly related.

\section{HYPOTHESIS 2}

Test 1 relationships between SPSSI and Estimation scores will be larger than relationships between SPSSI and SES scores.

\section{HYPOTHESIS 3}

The Test 1 scores of Estimation and SES will be positively and significantly related.

\section{HYPOTHESIS 4}

Goal attainment at mid-season is positively and significantly related to changes in SPSSI and Estimation scores at mid-season. HYPOTHESIS 5

Goal attainment at mid-season is more highly related to changes in SPSSI scores than to changes in Estimation scores. HYPOTHESIS 6

Changes in SPSSI scores at mid-season are positively and significantly related to changes in Estimation scores at mid-season. 


\section{HYPOTHESIS 7}

Changes in Estimation scores at mid-season are positively and significantly related to changes in SES scores at mid-season. HYPOTHESIS 8

Changes in SES scores at mid-season are more highly related to changes in Estimation scores at mid-season than to changes in SPSSI scores at midseason.

\section{HYPOTHESIS 9}

Goal attainment at post-season is positively and significantly related to changes in SPSSI and Estimation scores from mid-season to post-season. HYPOTHESIS 10

Goal attainment at post-season is more highly related to changes from mid-season to post-season in SPSSI as compared to Estimation scores. HYPOTHESIS 11

Changes in SPSSI scores from mid to post-season are positively and significantly related to changes in Estimation scores from mid to post-season. HYPOTHESIS 12

Changes in Estimation and SES scores from mid-season to post-season are positively and significantly related.

\section{HYPOTHESIS 13}

Changes in SES scores from mid-season to post-season are more highly related to changes in Estimation as compared to changes in SPSSI scores over the same time period. 


\section{Significance of the Study}

Figure 2 presents the model used in the present study to examine the manner in which self-estee $m$ is hypothesized to change. It is based on the premise that global self-esteem can be separated into multiple components of self-conception (Rosenberg, 1979). These components are hierarchially ordered on a dimension of generality after the model proposed by Shavelson, et. al. (1976). At lower levels (i.e., self-perceptions of swimming skills) self-conception is more situation specific and less stable than at higher levels. (i.e., global self-esteem and Estimation). Changes in skill are presumed to influence these congruent and more molecular self-perceptions. Changes in these specific self-perceptions should result in additional self-perception change at higher levels of generality.

The Estimation Scale developed by Sonstroem (1974) assesses self-perceptions of strength, coordination, endurance, speed, general physical competence, and athletic ability. Within the present study it represented a mid-level of generality. Estimation scores repeatedly have been shown to be related to physical fitness, to global self-esteem and to emotional adjustment in adolescent males (Sonstroem, 1974, 1976, 1978).

The research on goal setting in organizations has shown that challenging, specific goals lead to higher performance than easy goals, do your best goals, or no goals (Locke, Shaw, Saari, and Latham, 1981). Most of the 110 studies in Locke's review covered the effects of goal setting in business oriented tasks.

Locke et. al. (1981) and Locke and Latham's (1985) review articles have summarized eight important research findings : (1) Specific goals direct activity more effectively and reliably than vague or general goals (Locke, Mento, \& Katcher, 1978). (2) Difficult or challenging goals produce better 
performance than moderate or easy goals; the higher the goal, the higher the performance (Locke, 1968). (3) Short-term goals can be used as a means of attaining long range goals (Bandura \& Simon, 1977; Locke, Cartilidge, \& Knerr, 1970). (4) There are at least four mechanisms that explain why goal-setting improves performance. First, goal-setting directs activities (Locke \& Byran, 1969). Second, goal-setting regulates expenditure of one's effort (Locke, 1966). Third, goal-setting enhances persistence because effort is continued until the goal or subgoal is reached (Laporte \& Nath, 1976). Fourth, goal-setting can develop new strategies for improving performance (Latham \& Blades, 1975; Terborg, 1976). (5) Goal-setting only works if there is timely feedback showing performance or progress in relation to the goal (Locke et. al., 1981). (6) Goals must be accepted in order to be effective (Eriz \& Zidon, 1984). (7) Goal attainment is facilitated by a plan of action or strategy (Carroll \& Tosi, 1973). (8) Competition, a key element in sports, can be viewed as a form of goal-setting (Locke \& Latham, 1985).

The research on the effects of exercise on self-esteem has supported the fact that "a sense of well-being" is achieved through exercise. Sonstroem (1984) reviewed 16 studies testing the causal effects of exercise on self-esteem change and concluded that participation in exercise programs was associated with improved self-esteem measures.

According to Rosenberg (1979), individuals come to value personal resources which they assess as being successful in interactions with society. One of these particular attributes that this study addressed was goal attainment and its operant effects on self-esteem. Many self-esteem therapies incorporate goal attainment as a means of producing success experiences for individuals (e.g. Felker,1974, Loeffler \& Fiedler, 1979, Parker, 1983 and Tinel, 1983). 
Success experiences have also been correlated with positive self-esteem as well (Coopersmith, 1967; Rosenberg,1979).

Many studies also emphasize the use of realistic and performance goals (surpassing personal performance standards) rather than unrealistic and outcome goals (surpassing another's performance standards). A variety of research has been conducted concerning goal setting/attainment in business settings. In contrast, the dearth of studies in sports settings specifically, show the great need for research on goal setting/attainment and its operant effects on self-esteem in athletics.

\section{Definition of Terms}

Global Self-Esteem - One's overall self regard.

Self-Esteem - "The degree to which individuals feel positive about themselves"(Gergen, 1971 , p. 11). "Personal Judgement of worthiness"(Coopersmith, 1976, p. 5).

Physical Competence - "Evaluations regarding ability at vigorous exercise and sport activities in general" (Sonstroem \& Morgan, 1986, p. 31 ).

Goal Setting - To set a goal for a specific date or time period, whether it be proximal (short-term) or distal (long-term).

Goal Attainment - Attaining or accomplishing a pre-set goal.

Estimation - "To believe oneself is capable of achieving a measure of success at an activity"(Sonstroem, 1978).

Event - any race or series of races in a given swimming stroke or distance. There are 10 events in a high school meet; 8 individual events and 2 relays.

Meet - A series of events held in one program. A dual meet is a competition between two teams. 
Social Desirability - Defined as the inclination for individuals to respond to the social desirability of an item rather than its actual content (Jackson, 1984).

\section{Limitations}

1. A limitation of the present study was that the coaches may have been aware of the goal setting and might have had sessions where the coach of the respective teams had lectures or personal information on goal setting.

Additionally, some swimmers may have utilized goals before (sophomores, juniors, \& seniors) whereas some swimmers may have not (freshman). Therefore experience in goal setting could have been a factor.

2. Within the present study swim times were calculated from the self-reports of subjects rather than by more objective, mechanical methods.

3. A third limitation of the present study was that it was a pre-experimental study which did not utilize a control group. Therefore, the commonly recognized eight dangers to the internal validity of the research were not controlled. It cannot be concluded that the changes in self-esteem and estimation were due to swimming alone.

4. Measures of physical competence, self-perceptions of swimming skills, and goal attainment were study-developed and lacked proven validity. 


\section{CHAPTER II}

\section{REVIEW OF THE LITERATURE}

Chapter II is divided into five sections. The topics are as follows: SelfEsteem; Proposed Model for Measuring Self-Esteem; Estimation and the measurement of narrow traits; Self Perceptions of Swimming Skills; and Goal Setting/Goal attainment.

\section{Self-Esteem}

Self-esteem has been defined by Coopersmith $(1967$, p. 5) as "personal judgement of worthiness". A more recent definition is given by Rosenberg (1979) as "the self-concept's evaluative component based on cognitive comparisons and affect".

Gergen (1971) mentions that self-esteem is a positive evaluative component of self-conception. Self-esteem is generally regarded as the evaluative component of self-concept and is defined as "the extent to which the person feels positive about himself" (Gergen, 1971). While conservative definitions accord the processes of "description" to self-concept and "evaluation" to self-estee $m$, the two terms are often used interchangeabley (Shavelson, 1976).

Self-esteem (self-concept) was treated in the past as being global in nature (global self-esteem), but the theories today tend to lean more towards the multiple conception theory of the self. As mentioned earlier, it has been demonstrated repeatedly that individuals think differently of their different attributes and roles (Gergen, 1981). One experiment found that more than $50 \%$ or more of the responses of people asked to describe themselves used content specific to the particular situation (Block, 1952). This leads the majority of 
scholars to address self-esteem as a multidimensional construct (Gergen, 1981; Shavelson, 1976).

Rosenberg (1965) explains that self-esteem can have two different connotations: High self-esteem is that the person thinks he is "very good", or he thinks he is "good enough". Rosenberg (1965) goes on to mention "it is quite possible for a person to believe himself high in self-esteem when comparing himself to others, but consider himself low in self-esteem according to the standards he has set for himself". In other words, a person's self-esteem can be high in one sense but low in another. Rosenberg (1965) considers a person with high self-esteem as an individual who respects himself; considers himself worthy; does not necessarily consider himself better than others, but definitely does not consider himself worse; does not feel that he is the ultimate in perfection but on the contrary recognizes his limitations and expects to grow and improve. Positive self-esteem has long been a fundamental element of favorable life adjustment (Coopersmith, 1967; Gergen, 1971; Horney, 1950; Rosenberg, 1963,1979). A person with low selfesteem is considered to imply self-rejection, self-dissatisfaction, and selfcontempt. The individual lacks respect for the person he observes.

It would appear self-perceptions of greater importance to the individual are more closely related with feelings of overall self-regard. According to Rosenberg (1979) individuals come to value personal resources which they assess as being successful in societal reactions.

Self-esteem changes have also been associated with achievement (Scheier, 1979) and to feelings of competence (Kifer, 1975). Self-esteem therapy often includes enhancers such as goal setting, personalization to subject needs, modeling, success experiences, and positive personal reinforcement. A large number of self-esteem therapies incorporate goal 
attainment as a means of sensitizing the individual to success experiences (Felker, 1974; Loeffler \& Fiedler, 1979; Parker, 1983, and Tinde1, 1983). Success experiences have of ten been theorized as antecedents of positive self-esteem (Coopersmith, 1967; Rosenberg, 1979). Feedback, along with goal attainment, has been shown to increase self-esteem (Ewart, Taylor, Reese, \& DeBusk, 1983). Goal attainment and feedback have been presented in exercise programs as self-esteem enhancing agents, but have rarely been studied in a sport setting. Self-esteem has been measured with exercise programs. Sonstroem (1984) found that exercise involvement was closely related to elevated levels of self-esteem. Of importance to the present study is that four investigators have established self-perceptions of physical fitness and ability as a mediating variable in the fitness self-esteem relationship (Heaps, 1978; Leonardson, 1978; Neale, 1969; Sonstroem, 1974, 1976, 1978). All these studies found no association between physical fitness and self-esteem. They did show a relationship between self-perceptions of physical fitness and between self-perceptions and global self-esteem. This would support the idea that a person's feeling towards personal physical fitness is related to self-esteem, not the fitness itself.

Rosenberg (1965) notes that the ten-item Guttman Scale has satisfactory reproducibility and scalability. It is also mentioned that the scale is internally reliable and unidimensional and appears to have face validity. If the scale actually measure's low self-esteem, then we would expect those with low scores to appear depressed to others and to express feelings of discouragement and unhappiness. They would manifest symptoms of "neuroticism" or anxiety, hold a low sociometric status in the group, be described as commanding less respect than others and would feel that others have little respect for them. The evidence supports these expectations (Rosenberg, 1965). 
As recommended by Sonstroem and Morgan (in preparation) the Rosenberg Self-Esteem Scale (Rosenberg, 1965) was utilized in the present study as a measure of general self-worth or self-acceptance. The Rosenberg Self-Esteem Scale has been widely used in research for children and adults. Proposed Model for Measuring Self-Esteem

The proposed model revised to include non-self agents of self-esteem change such as goal attainment and self-perceptions of swimming skills, was study developed. The proposed model incorporates competence as a dimension of self-esteem and as a motivating agent integrated within components of self-conception which are organized hierarchially on the basis of situational generality. The model is arranged vertically in degrees of increasing situational generality from goal attainment at the base of the figure to global self-estee $m$ at the top. The model is represented in Figure 2 with the horizontal dimensions representing time which contains 3 data points of program testing. These points of program testing are separated by practice time and meets.

When using their model, Sonstroem and Morgan(1985) have recommended that a four month duration occur during testing especially if increased physical fitness is hypothesized to interact with feelings of competence and acceptance in modifying global self-esteem. Even though the present study did not incorporate fitness, the testing did last 15 weeks.

\section{Estimation Scale and the Measurement of Narrow Traits}

The development of the Physical Estimation and Attraction Scales (PEAS, Sonstroem, 1974) has provided a subscale (Estimation) capable of assessing self-perceptions of physical ability and sport skills. The items in the Estimation scale ask the individual to estimate his capabilities at physical 
activity and could be characterized as a measure of self-esteem regarding physical ability (Sonstroem, 1974). The Estimation score has been related to global seif-esteem (Sonstroem, 1976, 1978), to physical fitness (Neale, Sonstroem, \& Metz, 1969; Sonstroem, 1974, 1976), to aerobic power (Dishman, 1978), and to lack of maladjustment, personality disorder, or neuroticism in adolescent boys (Sonstroem, 1976).

Sonstroem (1974) concluded in his study of 710 males grades $9-12$ that estimation of one's physical ability bears a positive and significant relationship with physical fitness, with height, and with athletic experience. Another conclusion of the above study was that estimation of one's physical ability bears a positive and significant relationship with acceptance of self. Safrit, Wood, and Dishman (1985) in their final analysis, state the estimation component might have the strongest theoretical implications for a model dealing with involvement in physical activity. Fox, Corbin, and Couldry (1985) stated that physical estimation emerged as a key factor, particularly for females, in its relationship with self-esteem, fitness, and physical activity levels. The Estimation Scale appears to be a reliable and powerful instrument for assessing this construct. Three studies using adolescent boys failed to show a significant relationship between self-esteem and physical fitness (Neale, Sonstroem, \& Metz, 1969; Sonstroem, 1974, 1976). It was found, however, that estimation was significantly related to global self-esteem. The coefficients between estimation and self-esteem ranged from .21 to .53 . Competence has been proposed as a major dimension of self-esteem (Epstein, 1973; Gecas, 1982; and Harter, 1983). Sonstroem (1978) has stated that " a person must believe himself capable of achieving a measure of success at the activity". Sonstroem $(1974,1976)$ also obtained coefficients of .53 and .41 respectively between estimation and physical ability in high school boys. 
Sonstroem (1978) states some conclusions developed from studying the PEAS with various variables regarding male adolescent self-perceptions and perceptions of physical activities. The conclusions are as follows: Physical ability is not related to global self-esteem; Self-perceptions of physical ability are positively related to global self-esteem; self perceptions of physical ability are positively related to measured physical performances; and response distortion does not exert a major influence in replies to PEAS statements.

Validation of the Estimation scale was supported by Sonstroem (1974) with a correlation between Estimation and fitness which accounted for $28 \%$ of the variance in scores. This provided strong validating evidence for both the Estimation scale and its underlying construct.

The present study chose 33 Estimation items from the PEAS along with 6 new study developed estimation items that assessed self-perceptions and general athletic ability. The new item numbers were as follows: $18,23,30,35$, 47, and 49. Twenty social desirability items were also added to the estimation scale for response bias; item numbers: $11,15-16,21,26,28,31,37-38,41,42,45$, $54-57,59-60,63$, and 66 . It was therefore hypothesized in the present study that changes in estimation would be more positively related to changes in global self-esteem than the molecular levels of the model which included goal attainment and self-perceptions of swimming skills.

\section{Self-perceptions of Swimming Skills}

To date not much research has been done on the study of self-perceptions of specific sport skills. To understand the nature of self-perceptions of swimming skills, a review of the model (Figure 2) which outlines dimensions of self-esteem, physical competence, and self-perceptions of swimming skills is necessary. 
The model incorporates self-perceptions from the very specific to the very general. At the top of the hierarchy, global self-esteem was measured by the Rosenberg Self-Esteem Scale (1965). Items on this scale are very general statements of a person's self-worth such as, "I certainly feel useless at times," and "I am able to do things as well as most other people." These are general statements because they don't relate the feeling to a particular event or situation. More items from this scale can be found in Appendix B.

Self-perceptions of physical ability was measured by a modified estimation scale (Sonstroem, 1974) which can be seen in Appendix C. These items are more specific to the individual and may be more specific in feelings or situations. Some of the items are: "Vigorous exercise would leave my body tired and sore," or "I am better coordinated than most people I know," and "It takes me two days to recuperate from a physical workout." As can be seen, these statements relate to a more specific situation or feeling(physical ability).

Self-perceptions of swimming skills were measured by the study developed Self-Perceptions of Swimming Skills Inventory (SPSSI). These statements are for swimmers to rate their own specific swim skills to that of the average high school swimmer. The seven response options range from "Much Below Average" to "Much Above Average". These items are not only sport specific but specific within the sport of swimming itself. The five items that swimmers are asked to rate themselves are as follows: "Starts", "Turns", "Arm Stroke", "Kick", and "Coordination of Strokes". If these items were phrased in sentence form they would look something like: "Compared to other high school swimmers, I feel my starts are ("average"). As can be seen, all these items from the SPSSI are very specific to the sport of swimming. 
The purpose of the model again was to examine the manner in which self-esteem is hypothesized to change. Do very specific self-perceptions of a specific sport play any role in self-esteem change?

\title{
Goal Setting/ Goal Attainment
}

Mace (1935) found that when subjects are given specific goals they perform better than when subjects are simply told to "do their best". Goal setting is one topic that has been talked about by athletes and coaches alike. One of the most successful high school swimming coaches in the U.S., Dick Hannula, stated,

\begin{abstract}
"Motivation depends in a very large part on goal setting. The coach must have goals. The team must have goals. Each individual swimmer must have goals - real, vivid, living goals.... Goals keep everyone on target. Goals commit me to the work, time, pain and whatever else is part of the price of achieving success. Goals help to drive me.....Goals must be high enough to excite you, yet not so high that you cannot vividly imagine them. Goals must be attainable, but just out of reach for now" (Larsen, 1983).
\end{abstract}

There have been very few studies in the sports literature on goal setting, but there have been many studies in organizational settings or in laboratory experiments (Locke, Shaw, Saari, \& Latham, 1981; Locke \& Latham, 1984). In fact, to date there have been well over 100 studies of the effects of goal setting on task performance. Some of the organizational tasks include logging, clerical work, typing, computation, training, and much more.

Some of the research findings will be explained here but an in depth summary can be found in Locke et al. (1981). To summarize, the studies have found the following points. First, specific goals direct activity more effectively and reliably than vague or general goals (Locke, Mento, \& Katcher, 1978). A specific goal would be " I want to make twenty baskets today", or "I will work 
on the upbeat of my kick today." Second, difficult or challenging goals produce better performance than moderate or easy goals; the higher the goal the higher the performance (Locke, 1968). Goals should be difficult but at the same time realistic. "Do your best" is just not specific enough for the mind of most athletes. Third, short-term goals can be used as a means of attaining long-range goals (Bandura \& Simon, 1977; Locke, Cartledge, \& Knerr, 1970). Weekly or monthly goals are goals to keep a person reaching for that end of the season goal. Most athletes don't reach their goal overnight, but slowly work towards that goal. Attaining the short-term goals along the way can only help the athlete feel that he/she is succeeding. And fifth, goal setting only works if there is timely feedback showing performance or progressive relation to the goal (Locke et al.,1981). As mentioned above, the smaller, more frequent successes can lead to a positive end result.

Locke et al. (1981) reviewed 110 studies on the relationship of goal setting to task performance and 99 of the studies found that specific, hard goals led to significantly better performance than medium, easy, or "do your best goals". The result represented a success rate of 90 percent. There are still many questions though concerning goal setting in the sport context.

Three recent studies with goals and goal proximity yielded some interesting and contradictory results. Miller and McAuley (1987) examined the effect of a goal setting training program on basketball free throw performance, perceptions of success, and self-efficacy and found no significant differences between the goal training group (GT) and the non-goal training group (NT) for free throw accuracy. The data did suggest that a stronger relationship existed between self-efficacy and free throw performance for the GT group than for the NT group. The GT group reported significantly higher perceptions of success and self-efficacy than the NT 
group.

Hall, Weinberg, and Jackson (1987) utilized 94 subjects on a hand dynamometer endurance task and told subjects to hold one-third maximum contraction for as long as possible. Two groups were told to improve by $40 \mathrm{~s}$ and 70 s respectively while the third group was told to do your best. The 40 and 70 groups showed significant improvement than do your best group but the 40 and 70 group showed no difference in improvement. The authors concluded that although this study showed support for specific goals that lead to better performance than generalized "do your best" goals, the findings were inconsistent with the limited number of studies undertaken in physical activity settings.

Weinberg, Bruya, Longino, and Jackson (1988) tested the effects of goal proximity and goal specificity on endurance performance of young children in a two minute sit-up task. The authors concluded that the investigation provided mixed support for the effectiveness of goal setting in children. Although specific goals appear to enhance performance when compared to a "do your best" condition, no significant differences were found between distal and proximal goal conditions.

Although goal setting has been shown to improve task performance in organizational studies (Locke et al., 1981), the equivocal results with sport and physical activity have brought about even more questions to be answered by researchers. 


\section{CHAPTER III}

\section{PROCEDURE}

The procedure discussion is divided into five categories: Subjects, Study Design, Instruments Employed, Calculation of Study Variables, and Statistical Analysis of Data.

\section{Selection of Subjects}

The subjects in this study were male adolescents (grades $9-12$ ) of the Rhode Island Interscholastic Swimming League. There were nine schools that participated in the main study totaling 93 subjects. All subjects were volunteers and had their parents sign an informed consent form if they were under 18 years of age. All subjects were members of their respective varsity swim teams. Subject accessibility was facilitated through contacts with each coach of the respective teams as well as with their respective principals.

\section{Study Design}

Permission for the study was granted by the principal of each participating school as well as by the coach of the respective teams. Parental permission forms were also utilized seeing most of the subjects were under age 18. A parental consent form (Appendix A) was sent home to be signed by their parents (if under 18 ) and only subjects that returned the form participated in the study.

Data were collected at three time periods throughout the season; Pre-season (Test 1), Mid-season (Test 2), and Post-season (Test 3). The entire three tests were given between November 20, 1987 and $\mathrm{March} 4,1988$. The Pre-season testing was administered at the beginning of the practice season prior to any high school competition, Mid-season testing came in January 
(about the half way point in the season), and Post-season testing was administered immediately after the season. At Test 1 (Pre-season) swimmers used self-reports to record their best event, their best previous time in their best event, a proximal goal for January for their best event, and the importance of this goal was to them; this was all recorded on the study developed Personal Performance Goals Inventory (PPGI). Also at Test 1 the swimmers responded to the Rosenberg Self-esteem Scale (SES) (1965) to assess global self-esteem, to an Estimation scale (EST) (Sonstroem, 1974) to assess self-perceptions of physical ability, and to the study developed Self-perceptions of Swimming Skills Inventory (SPSSI) to assess self-perceptions of swimming skills. At Test 2, the PPGI was administered again but a goal was established this time for the State Championships and goal attainment was measured from Test 1 to Test 2. The SES, EST, and SPSSI were also administered at Test 2. At Test 3, all inventories were administered with only one change in the PPGI. No goals were made at Test 3. Test 1 and 2 took place in the respective natatorium for each team and Test 3 took place in a classroom at each of the team's respective schools. At each of the three testings, the author read the directions for filling in each inventory. Subjects were told to move six feet apart while the author asked for questions or necessary clarifications, and then instructed the subjects to complete the inventory.

Goal attainment was measured by the use of the study developed Personal Performance Goals Inventory (PPGI)(Appendix A). The titles of the PPGI were named for each of the tests: A-Pre (Test 1), B-Mid (Test 2), and C-Post (Test 3). Question number 4 and 8 from the PPGI's administered in Test 1 and 2 measured the importance of setting goals for each individual swimmer. Swimmers chose their best swimming event throughout this study for the 
PPGI. Self perceptions of swimming skills were measured by the study developed Self-perceptions of Swimming Skills Inventory (SPSSI). Athletic competence was measured by a revised Estimation Scale from the Physical Estimation and Attraction Scale (Sonstroem, 1978).

Those subjects who were absent on a particular test day had the inventories and directions left with the coach who was told to have them back to the author within two days. There were very few instances when this occurred.

Instruments Emoloved

Three inventories were combined in a 72 item questionnaire (Appendix B \& C). The three inventories included the Rosenberg Self Esteem Scale (items 1-10), a modified Estimation Scale (39 items) from the Physical Estimation and Attraction Scale (PEAS), and a social desirability scale (20 items). Three neutral items were also included to hide the nature of the questionnaire. The study developed Personal Performance Goals Inventory (Appendix E) and the study developed Self-Perceptions of Swimming Skills Inventory (Appendix D) were instruments employed in the study.

\section{Rosenberg Self-Esteem Scale}

The Rosenberg Self-Esteem Scale is a paper and pencil inventory developed by Rosenberg (1965) to measure subjects general self-esteem. The original four choice response format of the scale was revised to a five choice format to provide uniformity with the other scales. Response options included: "Strongly Agree", "Agree", "Undecided", "Disagree", and "Strongly Disagree". 
Scores are designed to range from 10 to 50 with lower scores representing lower self-esteem.

\section{Estimation Scale (modified from the PEAS)}

The modified estimation scale in the present study was utilized to assess general feelings of athletic competence. Estimation here means self-perceptions of physical ability. The items refer to an individual's potential at a given sport activity. Kuder-Richardson internal consistency coefficients (KR-20) of .87 for estimation have been obtained (Sonstroem, 1974), and a stability coefficient of .92 was obtained by Sonstroem (1976) with 40 high school males over a two week period. The estimation items had the identical response options as the Rosenberg Self-Esteem Scale.

It should be mentioned here that twenty social desirability items were incorporated to control for response distortion along with three neutral items to attempt to hide the nature of the questionnaire. The response options were again identical to the Rosenberg Self-Esteem Scale.

\section{Social Desirability Scale}

Social Desirability is characterized as the proclivity for subjects to respond to the social desirability of an item rather than its actual content (Jackson, 1984). The Social Desirability Scale (Jackson, 1984) is a 20 ite m paper and pencil test that assesses the tendency of subjects to respond to the social desirability of an item. As Jackson (1984) notes: "This scale was prepared to permit evaluation of profiles for responses primarily in terms of a prominent connotative property of items other than specific content, namely their 
desirability." Jackson (1984) has reported Kruder-Richardson internal consistency of .59 with high school males and test-retest reliabilities of .80 . The Social Desirability Scale items are in Appendix C comprised within the Estimation Scale as well. The social desirability items are as follows: 11, 15-16, $21,26,28,31,37-38,41,42,45,54-57,59-60,63$, and 66 .

\section{Self-Perceptions of Swimming Skills Inventory(SPSSI)}

The study developed SPSSI is a paper and pencil inventory. Subjects are asked to rate themselves as compared to the "average" high school swimmer on five items: "Starts", "Turns", "Arm Stroke", "Kick", and "Coordination of Strokes". Each of the five items has seven response options: "Much Below Average", "Below Average", "Slightly Below Average", "Average", Slightly Above Average", Above Average", "Much Above Average". Therefore, each item can have a score of 1-7 and a total of all five items of 5-35, with the higher scores representing better self-perceptions of swimming skills and the lower scores representing poorer self-perceptions of swimming skills.

\section{Personal Performance Goals Inventory(PPGI)}

The study developed PPGI (Appendix E) was utilized with the subjects so that they may give self-reports of their previous best time in what they perceived as their best high school individual event (there were a choice of eight). At Test 1 (Form A-Pre, Appendix E) question number one asked them to name their best event and question number two asked them to write down their previous best time in that event. The third question asked them to write down a proximal goal time for their best event for January, 1988 (or 
approximately mid-season). In question number four the swimmers also responded to how important this proximal goal was perceived as being. Four responses were possible: Not Very Important, Only Sort of Important, Pretty Important, and Very Important. At Test 2 (Form B-Mid, Appendix E) they responded to questions very similar to Test 1 . The one difference was to question number three concerning proximal goals. This time they were asked to set a goal for the State Championships. The same responses for goal importance were utilized. At Test 3 (form C-Post, Appendix E) swimmers only responded to two questions: What do you feel is your best event? and List your best time for the season in this event. No proximal goals were set and there were no questions or responses to goal importance because the swimmers were not setting goals at Test 3 .

\section{Calculation of Study Variables}

Measure of Performance (PERF): performance scores were calculated as standard scores which permitted combining times from different events. In each event an athletes standard swim score was calculated by subtracting mean time for that event from his personal time and dividing by the standard deviation for that time.

Performance change scores were calculated by standardizing individual change times in an event. The mean for change times in that event was subtracted from a swimmers personal change time and divided by the standard deviation for change times.

Measure of Goal Attainment (GAT): Goal attainment scores (GAT-MID) were calculated in the following manner. Pre-season goals were subtracted 
from Test 2 best times for each person in each event to obtain a raw goal attainment score. This resulted in lower values for better goal attainment. Standard scores for each event were then calculated by subtracting the mean goal achievement score for that event from each swimmer's goal achievement score and dividing the difference by the standard deviation of goal attainment for that event. Standard scores were then combined across events.

Goal attainment for post-season(GAT-POST) were calculated in the same manner with the time interval of pre-season to mid-season (Test 1 to Test 2) replaced by a time interval of mid-season to post-season (Test 2 to Test 3 ). Measure of Self-perceptions of Swimming Skills (SPSSI): The SPSSI can be examined in Appendix D. As stated in the directions to the subjects; The numbered items below represent specific abilities of high school Interscholastic swimmers. Please rate your abilities as compared to the average high school Interscholastic swimmer. The five specific skills were; Starts, Turns, Arm Stroke, Kick(legs), and Coordination of Strokes. The possible responses are; Much Below Average, Below Average, Slightly Below Average, Average, Slightly Above Average, Above Average, and Much Above Average. Therefore, for each specific skill the score could range from 1 to 7 and a total score, which the present study utilized to compare these scores, could range from 5 (very low perceptions of swimming skills) to a 35 (very high perceptions of swimming skills).

Measurement of Estimation (EST): All estimation items were recorded on general purpose NCS IBM answer sheets, form \#30423. The estimation item numbers have been mentioned earlier and can be found in Appendix C. Mean item responses were scored as follows; Strongly Agree $=5$, Agree $=4$, Undecided $=3$, Disagree $=2$, and Strongly Disagree $=1$. All hypotheses involving EST were 
tested by Pearson correlation coefficients and tests for significant differences between coefficients.

Measurement of Self-Esteem (SES): The Rosenberg Self-Esteem Scale (1965) can be examined in Appendix B. These 10 items were also recorded on the general purpose NCS IBM answer sheets, form \#30423. All self-esteem items had the same response options as EST and were scored in the same fashion as the EST items. Both the EST scores and SES scores were calculated at the computer center of the University of Rhode Island.

\section{Statistical Analysis of Data}

Responses to psychological inventories were answered on IBM forms and were scored at the Academic Computer Center at the University of Rhode Island. Goal responses and swim times were entered on computer files by the author. Statistical tests of hypotheses included Pearson correlation, and t-tests for significant differences in coefficients and were conducted utilizing SPSSX software. 


\section{Chapter 4}

\section{Results}

Chapter four is divided into seven sections. These are: (a) Descriptive Statistics, (b) Tests of Hypotheses, (c) Summary of Hypotheses Testing, (d) Discussion, (e) Practical Implications, (f) Recommendations for Future Research, and (g) Conclusions. Throughout Chapter 4 pre-season testing will will be abbreviated as $\mathrm{T} 1$; mid-season testing as $\mathrm{T} 2$, and post-season testing as T3.

\section{Descriotive Statistics}

\section{Swimming Performance}

Table 1 contains the means and standard deviations for swimming performances. These values represent previous best competitive times in each swimmer's best event (second column of Table 1). The freestyle events are listed first and are broken down into the various race distances: $50 \mathrm{yd}, 100 \mathrm{yd}$, $200 \mathrm{yd}$, and $500 \mathrm{yd}$. The backstroke, breaststroke, and butterfly are all $100 \mathrm{yd}$. events. On the average, for the 1987-88 season, the times are somewhat equivalent to previous years for the State of Rhode Island.

In the $50 \mathrm{yd}$. free the range was from $23 \mathrm{sec}$. to $40 \mathrm{sec}$. with a mean of $29.05 \mathrm{sec}$. The $100 \mathrm{yd}$. free ranged from $50 \mathrm{sec}$. to $100 \mathrm{sec}$. with a mean of 65.14 sec. In the $200 \mathrm{yd}$. free the range was $108 \mathrm{sec}$. at the bottom to $160 \mathrm{sec}$. at the top with a mean of $128.07 \mathrm{sec}$. The $500 \mathrm{yd}$. free had a range of $287 \mathrm{sec}$. to 581 sec. and a mean of $375.76 \mathrm{sec}$. The $100 \mathrm{yd}$. backstroke ranged from $60 \mathrm{sec}$. to 84 sec. with a mean performance time of $67.81 \mathrm{sec}$. In the $100 \mathrm{yd}$. breaststroke, the low was $62 \mathrm{sec}$. and the high was $84 \mathrm{sec}$. with a mean of $71.09 \mathrm{sec}$. And 
finally, the $100 \mathrm{yd}$. butterfly had a range of $59 \mathrm{sec}$. to $72 \mathrm{sec}$. and a mean of $65.41 \mathrm{sec}$. Statistics could not be computed for the $200 \mathrm{yd}$. Individual Medley (200 IM) because the measure was missing in every case.

Table 1

Means and Tests for Change - Swim Times (Performances)

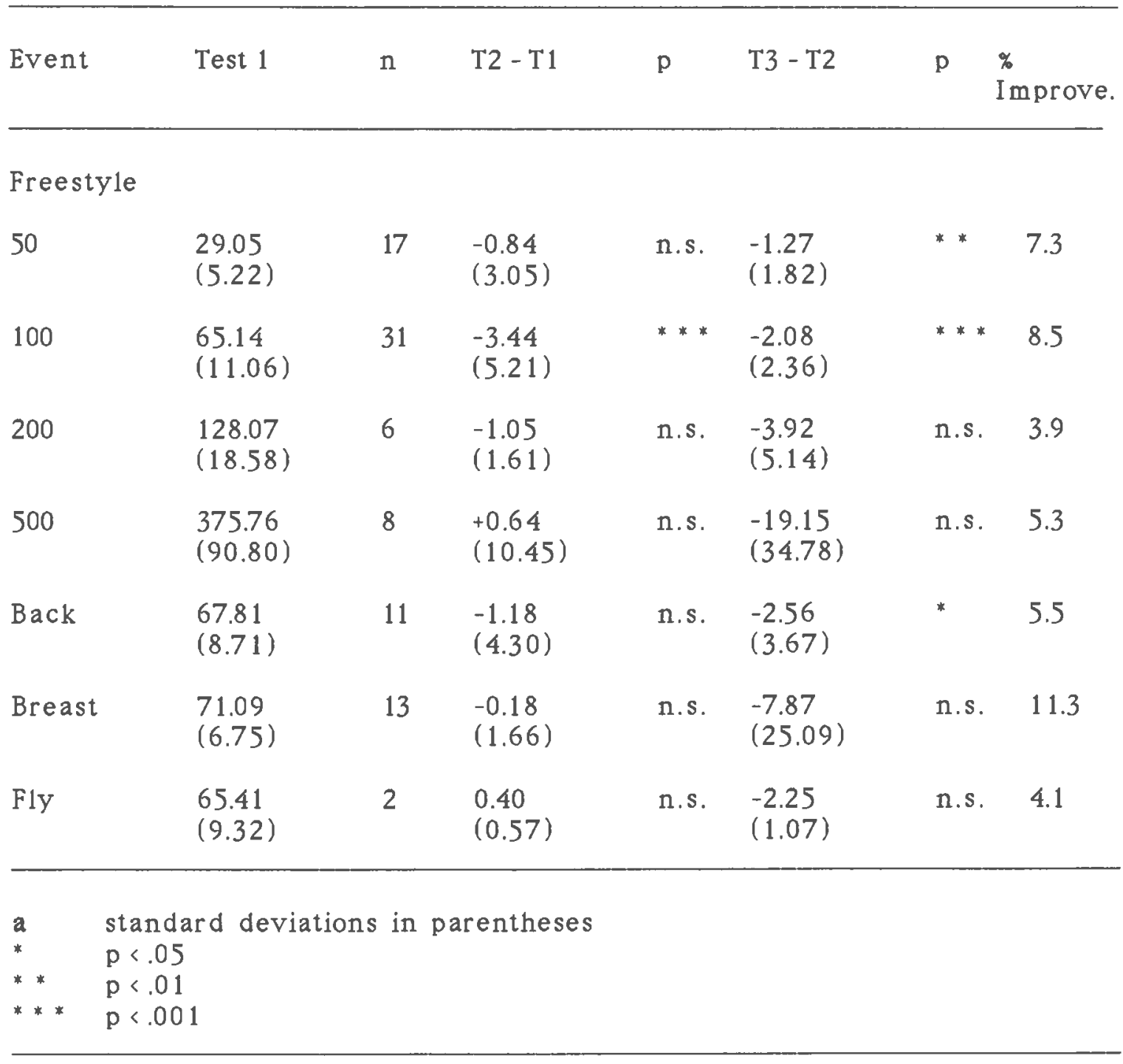

Table 1 presents mid-season improvements in column 4. From T1 to T2 improvements were only seen in the $100 \mathrm{yd}$. free which was significant at the .001 level of probability. In the $500 \mathrm{yd}$. free, the mean actually increased 
which showed an increase (added time to T1 mean scores) in time. None of the other events showed any significant improvements although swim times did decrease.

From T2 to T3 two events showed statistically significant improvements at the .001 level of probability; the $50 \mathrm{yd}$. free and the $100 \mathrm{yd}$. free. The $100 \mathrm{yd}$. back was also able to show statistically significant improvement at the .05 level of probability. The remainder of the events failed to show significant improvements.

Interpretation of swim improvements must consider that the majority of these athletes had already been swimming competitively for three to ten years. Column eight of Table 1 lists average percent improvements in each event over the course of the season. It's observed that considerable improvement was experienced in a majority of events when improvement is calculated as a percentage of $\mathrm{T} 1$ times. As an example, the 13 breaststrokers improved $11.3 \%$ over an original average time of 71.09 seconds. The reason for the limited number of statistically significant improvements seems to involve the large amount of variability in improvement. In all cases except one the standard deviations for improvement times are larger than the means for the same improvement time. 
Table 2

Means and Tests for Change - Self-Perceptions ${ }^{2}$

Variable

Test 1

$\mathrm{T} 2$ - T1

$\mathrm{p}$

T3 - T2

$\mathrm{p}$

SPSS I

Start

4.54

$+0.08$

n.s.

$+0.06$

n.s.

Turns

4.15

$+0.18$

n.s.

$+0.13$

Arms

\subsection{2}

$+0.08$

n.s.

$+0.09$

n.s.

Kick

$$
3.84
$$

(1.53)

Coord.

$$
4.59
$$

$+0.09$

n.s.

$+0.17$

(1.29)

Total

\subsection{1}

(5.44)

$+0.75$

(3.10)

EST

\subsection{4}

(0.45)

$+0.08$

$(0.38)$

SES

$$
3.96
$$

$+0.12$

(0.51)

(0.42)

SD

$\begin{array}{ll}3.08 & +0.01 \\ (0.29) & \end{array}$

n.s.

n.s.

\section{$\mathrm{N}=93$}

* $p<.05$

$* * \quad p<.01$

$* * * \quad p<.001$ 


\section{Self-perception Variables}

Table 2 contains the means and standard deviations for self-perceptions of swimming skills (SPSSI), estimation scores (EST), self-esteem scores (SES), and social desirability scores (SD). At T1 subjects rated their arm stroke best and their kick the poorest. This rating may be due to the fact that probably more than $65 \%$ of swimming strokes (except breaststroke) receive propulsion from the arms. For a more in depth view of swimming strokes the reader is referred to Counsilman (1977) and Maglischo (1982).

The estimation mean score of $3.64(s d=0.45)$ was compared to two other studies (Sonstroem, 1974; \& Reiss, 1986) after adjusting the score for equivalence with a scale of 33 items and a true-false response format. The adjusted EST score of 24.024 was considerably higher than both Sonstroem's study using high school males (EST $=20.40$ ), and Reiss's study with adult females (EST $=19.97$ ). It is recognized that the present study involved high school athletes.

From T1 to T2 EST scores $(+0.08)$ were significantly improved at the .05 level of probability. From T2 to T3, scores again were significantly improved and this time at the .01 level of probability $(+0.06)$.

Self-esteem scores at T1(3.96) were compared to Crandall (1973) and Rosenberg (1965) and found to be somewhat higher than both these studies. Self-esteem scores improved significantly at the .01 level of probability at T2 but had no significant improvement at $\mathrm{T} 3$.

\section{Tests of the Hypotheses}

Hypothesis 1 to Hypothesis 3 were tested by means of Pearson correlation coefficients obtained between self-perception variables at Test 1 
and by tests for significant differences between these coefficients. Table 3 presents a correlation matrix of coefficients obtained at Test 1 .

Hypothesis 1: The Test 1 scores of SPSSI and Estimation (EST) will be positively and significantly related.

As can be observed in Table 3 the coefficient between SPSSI and EST was $0.59(p<.001)$. It was concluded that SPSSI and EST are positively and significantly related. Self-evaluations of specific swim skills in male high school varsity swimmers are related to overall evaluations of physical ability.

Hyoothesis 2: Test 1 relationships between SPSSI and EST scores will be larger than relationships between SPSSI and SES scores.

This hypothesis was tested by means of a t-ratio for dependent correlation coefficients(Ferguson, 1971). The t-ratio is presented below:

$$
t=\frac{\left(r_{12}-r_{13}\right) \sqrt{(N-3)\left(1+r_{23}\right)}}{\sqrt{2\left(1-r_{12}{ }^{2}-r_{13}{ }^{2}-r_{23}{ }^{2}+2 r_{12} r_{13} r_{23}\right)}}
$$

In the present case the test was made to determine whether the coefficient of .592 between SPSSI and Estimation scores was significantly larger than the coefficient of .188 between SPSSI and self-esteem scores. A $t$ value of 4.01 ( $p<.001$ ) was obtained providing support for the research hypothesis. It was concluded that self-evaluation of specific swim skills in male high school varsity swimmers are more highly related to overall evaluations of physical ability than they are to global self-esteem. 
Hypothesis 3: The Test 1 scores of EST and SES will be positively and significantly related.

As can be observed in Table 3 the coefficient between EST and SES was 0.30 ( $p<.01)$. It was concluded that EST and SES are positively and significantly related. General self-evaluations of physical ability in male high school swimmers are related to self-esteem scores.

Table 3

Relationships Among Self-Perception Variables and Previous Performance At Test $1^{d}$

\begin{tabular}{|c|c|c|c|c|c|c|}
\hline & & EST & SES & PERE & $\underline{\mathrm{SD}}$ & GRADE \\
\hline SPSS I & & $.59^{c}$ & $.19^{a}$ & $.50^{c}$ & .05 & .01 \\
\hline EST & & --- & $.30^{b}$ & $.33^{c}$ & -.02 & -.03 \\
\hline SES & & $\ldots$ & --- & $.22^{\mathrm{a}}$ & $-.20^{a}$ & $.23^{b}$ \\
\hline PERF & & -- & --- & -- & .01 & $.23^{a}$ \\
\hline $\mathrm{SD}$ & & --- & $\ldots$ & --- & --- & .10 \\
\hline $\begin{array}{l}a \\
b \\
c \\
d\end{array}$ & $\begin{array}{l}p<.05 \\
p<.01 \\
p<.001 \\
\text { values }\end{array}$ & corrected for & direction & & & \\
\hline
\end{tabular}

Hypotheses 4 to 8 were tested by means of Pearson correlation coefficients and tests for significant differences between these coefficients. Change scores (Test 2 values minus Test 1 values) were examined for the selfperception variables. Goal attainment scores (GAT-MID) were calculated in the following manner. Pre-season goals were subtracted from Test 2 times for each person in each event to obtain a raw goal attainment score. This resulted 
in lower values for better goal attainment. Standard scores for each event were then calculated by subtracting the mean goal achievement score for that event from each swimmer's goal achievement score and dividing the difference by the standard deviation of goal attainment for that event. Standard scores were then combined across events.

Table 4 presents Pearson $r$ coefficients among self-perception change scores and standardized goal attainment scores. In all cases coefficients are corrected for direction. Positive values represent positive relationships.

Hypothesis 4: Goal attainment at mid-season is positively and significantly related to changes in SPSSI and Estimation scores at mid-season.

Examination of Table 4 (row 1 ) reveals that goal attainment was significantly related $(p<.001)$ to actual swimming improvement (PERF, T2 T1). However, goal attainment was not significantly related to changes in SPSSI or EST. Based upon these analyses it was concluded that goal attainment at mid-season in male secondary level swimmers is unrelated to changes in self-perceptions of swim skills or to changes in estimation scores.

Table 4

Correlation Matrix of Study Variables - (Test 2 - Test 1)

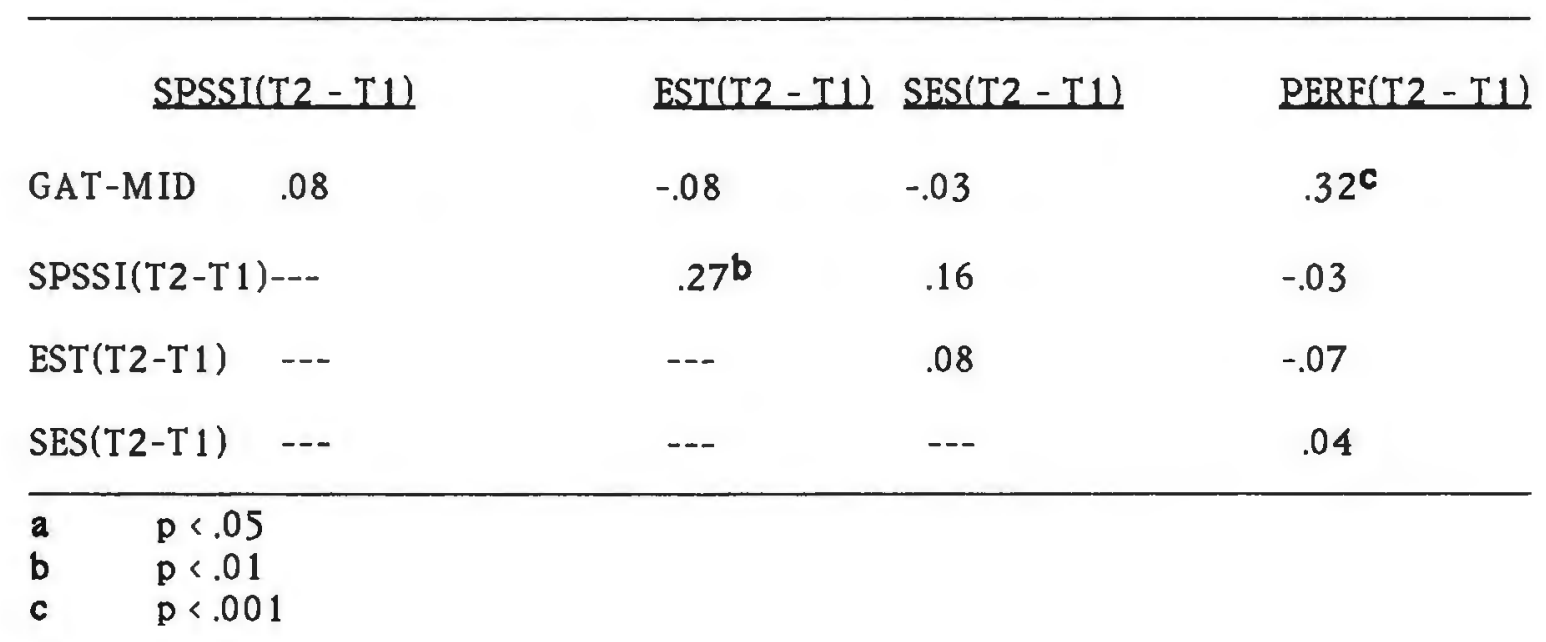


Hypothesis 5: Goal attainment at mid-season is more highly related to changes in SPSSI scores than to changes in Estimation scores.

As may be observed in Table 4, a coefficient of .08 was obtained between goal attainment and SPSSI changes and a coefficient of -.08 was obtained between goal attainment and estimation changes. This difference in coefficients was tested for significance by the same t-ratio employed in the test for Hypothesis 1. A t value of 1.26 was obtained. A t value of 1.67 was needed for significance at the .05 level of probability. Therefore, the research hypothesis was not supported. Also, it must be remembered from the test of hypothesis 4 that the relationships between goal attainment and either SPSSI or estimation changes were not significant.

Hypothesis 6: Changes in SPSSI scores at mid-season are positively and significantly related to changes in Estimation scores at mid-season.

Examination of Table 4 reveals a coefficient of 0.27 between changes at mid-season of SPSSI and Estimation. This indicated a significant positive relationship at a .01 level of probability. It was concluded that changes in self-perceptions of specific swim skills at mid-season are associated positively with changes in overall evaluation of physical ability in male high school swimmers.

Hypothesis 7: Changes in Estimation scores at mid-season are positively and significantly related to changes in SES scores at mid-season.

As observed in Table 4 a coefficient of .08 was calculated between changes in EST scores and SES scores. This failed to indicate a significant relationship between these two variables. Therefore it was concluded that changes in EST scores at mid-season are not related to changes in SES scores at mid-season for male high school swimmers. Hypothesis seven was therefore not supported. 
Hypothesis 8: Changes in SES scores at mid-season are more highly related to changes in Estimation scores at mid-season than to changes in SPSSI scores at mid-season.

Table 4 reveals that changes in self-esteem were more closely associated with changes in SPSSI scores( $r=.16)$ than with changes in estimation scores $(r=.08)$. The direction if these results fails to support the research hypothesis. A t-test for significant differences in coefficient size produced a nonsignificant $t$-value of 0.61 . Within the present study it was concluded that changes in self-esteem at mid-season are not more closely associated with changes in estimation scores as opposed to changes in SPSSI scores.

Hypotheses 9 to 12 were tested again by means of Pearson $r$ coefficients and by $\mathrm{t}$-tests for significant differences between these coefficients. Variables were calculated in the same manner as in tests of hypotheses 4 to 8 . The time interval of pre-season to mid-season (Test 1 to Test 2) was replaced by a time interval of mid-season to post-season (Test 2 to Test 3). Correlations among changes in self-perception variables and goal achievement from midseason to post-season are presented in Table 5.

Hypothesis 2: Goal attainment at post-season is positively and significantly related to changes in SPSSI and Estimation scores from midseason to post-season.

Examination of Table 5 (row 1) reveals that goal attainment was significantly related $(\mathrm{p}<.001)$ to actual swimming improvement (PERF, T3 T2). However, goal attainment was not significantly related to changes in SPSSI or EST. Based upon these analysis it was concluded that goal attainment at post-season in male secondary level swimmers is unrelated to changes in self-perceptions of swimming skills or to changes in estimation scores. 
Hypothesis 10: Goal attainment at post-season is more highly related to changes from mid-season to post-season in SPSSI as compared to Estimation scores.

As may be observed in Table 5, a coefficient of .03 was obtained between goal attainment and SPSSI changes and a coefficient of .06 was obtained between goal attainment and estimation changes. This difference in coefficients was tested for significance by the same t-ratio employed in the test of Hypothesis 4. The t-test produced a non-significant $t$ value of 0.21 . Therefore the research hypothesis was not supported. Also it must be remembered from the test of Hypothesis 9 that the relationships between goal attainment and either SPSSI or estimation changes were significant.

Hypothesis 11: Changes in SPSSI scores from mid to post-season are positively and significantly related to changes in Estimation scores from mid to post-season.

Examination of Table 5 reveals a coefficient of 0.19 between changes at post-season between SPSSI and estimation. This indicated a significant positive relationship at a .05 level of probability. It was concluded that changes in self-perceptions of specific swim skills at post-season are associated positively with changes in overall evaluations of physical ability in male high school swimmers. 
Table 5

Correlation Matrix of Study Variables -- (Test 3 - Test 2)

\begin{tabular}{|c|c|c|c|c|}
\hline & $\begin{array}{l}\text { SPSSI } \\
(T 3-T 2)\end{array}$ & $\begin{array}{l}\text { EST } \\
\text { (T3-T2) }\end{array}$ & $\begin{array}{l}\text { SES } \\
\text { (T3-T2) }\end{array}$ & $\begin{array}{l}\text { PERF } \\
\mathrm{T} 3-\mathrm{T} 2)\end{array}$ \\
\hline GAT - POST & .03 & .06 & -.03 & $.49 \mathrm{C}$ \\
\hline SPSSI (T3 - T2) & --- & $.19^{a}$ & -.05 & -.05 \\
\hline EST (T3 - T2) & -- & -- & $.24^{b}$ & .02 \\
\hline SES (T3 - T2) & --- & -- & --- & -.08 \\
\hline $\begin{array}{ll}\mathrm{a} & \mathrm{p}<.05 \\
\mathrm{~b} & \mathrm{p}<.01 \\
\mathrm{c} & \mathrm{p}<.001\end{array}$ & & & & \\
\hline
\end{tabular}

Hypothesis 12: Changes in Estimation and SES scores from mid-season to post-season are positively and significantly related.

As observed in Table 5 a coefficient of 0.24 between changes at postseason in EST and SES scores. This indicated a positive relationship at a .01 level of probability. It was concluded that changes in evaluations of physical ability are associated positively to changes in self-esteem in male high school swimmers.

Hypothesis 13: Changes in SES scores from mid-season to post-season are more highly related to changes in Estimation as compared to changes in SPSSI scores over the same time period.

Table 5 reveals that changes in self-estee $\mathrm{m}$ are more highly related to changes in EST $(0.24, p<.01)$ than to changes in SPSSI $(-.05)$. The direction of these results supports the research hypothesis. A t-test for significant differences in coefficient size produced a significant $t$ value of $2.23, p<.05$. 
Within the present study it was concluded that changes in self-esteem at postseason are more closely related to changes in Estimation than to changes in SPSSI scores. Therefore, changes in SES scores of male high school swimmers are more closely related to changes in EST scores than to changes in evaluations of specific swimming skills.

\section{Summary of Hypothesis Testing}

A summary of hypothesis testing is seen in Table 6. Of the 13 research hypotheses, 7 were retained $(1,2,3,6,11,12, \& 13)$. Of the six remaining hypotheses that were not supported, four of the hypotheses were related to goal attainment. 
Table 6

Summary of Hypothesis Testing

\begin{tabular}{|c|c|c|}
\hline Hypothesis & $\begin{array}{l}\text { Relationship Proposed } \\
\text { Pre-season }\end{array}$ & Cenclusion \\
\hline 1 & SPSSI \& EST & + \\
\hline 2 & SPSSI \& EST > SPSSI \& SES & + \\
\hline \multirow[t]{2}{*}{3} & EST \& SE & + \\
\hline & Pre to Mid-season & \\
\hline 4 & GAT \& SPSSI, EST changes & 0 \\
\hline 5 & GAT \& SPSSI changes > GAT \& EST changes & 0 \\
\hline 6 & SPSSI change \& EST change & + \\
\hline 7 & EST change \& SES change & 0 \\
\hline \multirow[t]{2}{*}{8} & SES \& EST changes > SES \& SPSSI changes & 0 \\
\hline & Mid to Post-season & \\
\hline 9 & GAT \& SPSSI changes, EST changes & 0 \\
\hline 10 & GAT \& SPSSI change > GAT \& EST change & 0 \\
\hline 11 & SPSSI change \& EST change & + \\
\hline 12 & EST change \& SES change & + \\
\hline 13 & EST \& SES changes > SPSSI \& SES change & + \\
\hline $\begin{array}{l}+ \\
0\end{array}$ & $\begin{array}{l}\text { the research hypothesis was supported } \\
\text { the research hypothesis was not suppor }\end{array}$ & \\
\hline
\end{tabular}




\section{Discussion}

Within the present study goal attainment did not contribute to improvement in self-perceptions, either in terms of SES, EST, or SPSSI. It should be mentioned that only 11 of 81 subjects reached their pre-set goals at mid-season and only 20 of 93 reached their goals at post-season. This may have been due to the fact that no formal goal training program was implemented to inform the swimmers on how to set goals that are realistic. Only the experienced swimmers may have utilized goal setting in a formal way in the past.

However, relationships between self-perception variables within the model tended to be supported. Seven of nine hypotheses involving selfperception variables were supported (Table 6). Additionally, static relationships between self-perception variables and performance were supported across all testing times (Table 7). Across all 3 tests, correlation coefficients ( $r$ 's) between performance and self-perceptions of swimming skills and Estimation were significant as would be hypothesized by the model. Over the course of the season hypothesized mean relationships between selfperception variables tended to increase (Table 7). This may reflect increases in singularity of purpose over the course of the season(swimmers were more prone to base self-esteem assessments on their self-perceptions of swimming competence).

Six of the 13 hypotheses proposed relationships between change scores in the self-perception variables. Four of these six proposed relationships were significant. Both of the two hypotheses that were not significant involved a single relationship, that between changes in self-esteem scores and 
estimation from pre-to mid season. The obtained Pearson $r$ between changes in estimation and changes in self-esteem was only .08 . This value was not significant (Hypothesis 7) and certainly was not larger than the Pearson $r$ between self-esteem and self-perception of swimming skills changes (Hypothesis 8 ). The proposed relationship between changes in self-perception of swimming skills and estimation from pre to mid-season was significant. Hypothesized change relationships between self-perceptions of swimming skills and estimation and between estimation and self-esteem from mid to postseason were both significant. The present study is seen as providing a degree of validity for both static and developmental relationships between selfperception variables proposed by the model.

As may be observed from Table 4 and Table 5 changes in self-perception variables were unrelated to changes in actual swimming performance. Previously, it was concluded that self-perception changes were unrelated to goal attainment. The present study, therefore, is unable to identify any objective criterion in terms of swim performance that was associated with these self-perception changes. However, examinations of Table 1 indicates that significant improvement was made in only four of the swim events over the three testing periods. It is possible that testing for improvement twice during the season may have served to shrink improvement scales of all variables within the study. Thus, the presence of truncated scales may have reduced the size of coefficients. 
Table 7

Static Relationships Between Model Variables Over The Course of A Season

\begin{tabular}{|c|c|c|c|c|}
\hline$\frac{\text { Variable }}{\text { Test } 1}$ & EST & SPSSI & $\begin{array}{l}\text { Mean } \\
\text { Validity } r\end{array}$ & PERE \\
\hline SES & $.297^{b}$ & $.188^{a}$ & & $.220^{2}$ \\
\hline EST & --- & $.592^{\mathrm{c}}$ & .444 & $.333^{c}$ \\
\hline SPSSI & -.- &.-- & & $.495^{c}$ \\
\hline Test 2 & & & & \\
\hline SES & $.433^{c}$ & $.192^{a}$ & & .059 \\
\hline EST & -- &, $489 \mathrm{c}$ & .461 & $.428^{\mathrm{C}}$ \\
\hline SPSSI & --- & -- & & $.470^{\mathrm{C}}$ \\
\hline Test 3 & & & & \\
\hline SES & $.555^{c}$ & $.347^{c}$ & & $.173^{a}$ \\
\hline EST & -- & $.510^{c}$ & .532 & $.322^{c}$ \\
\hline SPSSI & --- & --- & & $.418^{c}$ \\
\hline $\begin{array}{ll}\mathbf{a} & \mathrm{p}<.05 \\
\mathrm{~b} & \mathrm{p}<.01 \\
\mathrm{c} & \mathrm{p}<.001\end{array}$ & & & & \\
\hline
\end{tabular}

The sport of swimming is a very demanding and competitive sport.

Other factors that may have had an effect on any one of the models' variables are situations such as winning, losing, placing in dual meets or championships, and competition itself.

In todays society it seems that the winner gets all of the recognition and the second place athlete gets lost in the shuffle. The media, coaches, and parents always seem to congratulate the winner and give less than positive 
reinforcement to the second place finisher. Questions such as, "What went wrong out there?", or "Why did you let him beat you?" are common. This type of attention to the second place finisher could be very discouraging, especially if that athlete has finished in a lifetime best time! The same circumstances can be related to teams that win and teams that lose. On winning teams most of the athletes feel quite good about their performances because their team is always winning, whereas the athletes of losing teams tend to feel that they are not performing to their capabilities because their team is losing most of the time. While all of this may be true in some cases, it is in no way true for everyone.

As mentioned above, placing could also play a very big role on the selfperceptions of swimmers. A swimmer swimming for team A may be the best on team A but when competing with teams B,C, D, etc., he may never place in the top three (top three score points in dual meets). Therefore he may feel that he is below average in his swimming skills. Placing could also work in a positive direction as can well be understood.

Competing on a high school team can also make a difference in selfperceptions of physical ability. Just making a high school team may make a swimmer feel on top of the world, and even though he may be below average in his league, just the fact of being a "team member" is all it takes. Although making a high school team is great there are swimmers who make the team and never swim "official". Swimming official means that you are in position to score points, swimming as "exhibition" means you are just swimming for a personal time and not to score points. These exhibition swimmers may feel, and in most instances do, like they are not making any contribution to themselves or the team.

League Divisions can also influence self-perceptions of swimmers. For instance, the Rhode Island Interscholastic League, Inc. has two divisions for 
swimming, an $\mathrm{A}$ division and a $\mathrm{B}$ division. The $\mathrm{A}$ division includes the stronger teams on the average and the B division includes the weaker teams. Most of the swimmers are aware of this and this awareness can possibly lower or raise self-perceptions of swimming skills for each individual.

As far as goal setting and goal attainment is concerned, there are some factors that may explain the nonsignificant goal attainment results of the present study. The fact that only 11 swimmers at mid-season and 20 swimmers at post-season attained their goals may have been due to the fact that most teams in the study did not use formal goal setting as part of their training program. Swimmers may have had personal verbal goals but this study may have provided the first opportunity for these swimmers to actually write their goals down. As noted by Locke et al. (1981) setting realistic but challenging goals is a recommendation for goal setting. In the present study, some swimmers were probably inexperienced with goal setting and setting realistic goals may have been very difficult for them. On the other hand, the more experienced swimmers may have been trying to impress their peers by setting unrealistic goals that were almost impossible to attain. In the present study the only important variable that goal attainment related to was swimming improvement at both the mid and post testings. This implies that goal attainment is related to swimming improvement. It should be recognized however, that these are actually dependent variables since both employ T2 (or Test 3) swim times in their calculation.

In summary, there are many extraneous factors that may have contributed to the results of the present study and are mentioned above. The use of goal setting and goal attainment, at least within the limits of the present study, was shown to have very little support for its use with male high school 
swimmers as it relates to self-evaluations of physical ability and selfperceptions of swimming skills.

\section{Practical Implications}

Self-evaluations of specific swim skills in male high school varsity swimmers were found to be related to overall evaluations of physical ability. This implies that coaches should try to raise their swimmers' evaluations about their skills in order that they may become more positive about their swimming in general. The more positive a swimmer is, the more confidence he may have when it comes to competition.

Estimation of physical ability was also found to be related to global selfesteem. An example from the literature on physical ability involved "experts" who rated 14-16 year old boys on several demonstrated sport skills (Maehr, Mensing, \& Natzger, 1962). Boys who received positive approval significantly increased their own ratings of skill ability, whereas boys who were given negative feedback significantly decreased their ratings of personal skill. Therefore coaches should use positive feedback whenever possible to attempt to increase the swimming skills of their athletes. The swimmers' selfevaluations of physical ability could in turn raise their global self-esteem levels.

Goal attainment was found to be significantly related to actual swimming improvement. Although none of the other study variables were related to goal attainment, the fact that goal attainment was related to actual swimming improvement should help coaches understand that a more stringent goal setting program could actually have positive effects on swimming improvement. Therefore, coaches should not stop using goal setting or feel it is of no use in attempting to improve swimming performance. 


\section{Recommendations for Future Research}

Although the present study yielded no significant correlations between goal attainment and either self-esteem, self-evaluations of physical ability, or self-perceptions of swimming skills, the use of a goal setting training program to educate athletes on the use of goal setting may provide the hypothesized relationships If the swimmers of the present study knew how to create realistic goals, the results may have been different.

The present study utilized male high school varsity swimmers as subjects. Replication of the same study parameters should be researched with female high school varsity swimmers. Also, the present study could also be used with age group swimmers (young swimmers, ages $8-18$ ), and even collegiate male and female swimmers. The testing of elite and even Olympic swimmers is another possibility.

A simple revision of the Self-perceptions of Swimming Skills Inventory (SPSSI) and the Personal Performance Goals Inventory (PPGI) could make the study useful for any sport, i.e., football, basketball, or tennis, etc. A tennis skills inventory could include such specific skills as forehand, backhand, volley, and serve. Goals could be set for almost any sport whether they be long-term or short-term.

The present study relied on self reports of actual performance. More control could be used to make sure that the reports on actual performance are actually true. The use of only one team may help this situation somewhat, although in the present study, it did not seem as if subjects were reporting false performance times. 


\section{Conclusions}

The present study supported the following hypotheses in relation to the modified model for examining the manner in which self-esteem is hypothesized to change in male high school varsity swimmers grades $9-12$.

1. Self-perceptions of swimming skills and estimation were positively and significantly related at pre-season.

2. Pre-season relationships between self-perceptions of swimming skills and estimation scores were larger than relationships between selfperceptions of swimming skills and self-esteem scores.

3. Pre-season scores of estimation and self-esteem were positively and significantly related.

4. Changes in self-perceptions of swimming skills at mid-season were positively and significantly related to changes in estimation scores at mid-season.

5. Changes in self-perceptions of swimming skills from mid to postseason were positively and significantly related to changes in estimation scores from mid to post-season.

6. Changes in estimation and self-esteem scores from mid to postseason were positively and significantly related.

7. Changes in self-esteem scores from mid to post-season were more highly related to changes in estimation as compared to changes in selfperceptions of swimming skills scores over the same time period.

8. Goal attainment was positively and significantly related to actual swimming improvement from pre to mid-season. 


\section{References}

Bandura, A., \& Simon, K.M. (1977). The role of proximal intentions in self regulation of refractory behavior . Cognitive Theraoy and Research 1 . 177-193.

Carroll, S.J., \& Tosi, H.L. (1973). Management by Objectives. New York: MacMillan.

Coopersmith, S. (1967). The antecedents of self-esteem. San Francisco: Freeman.

Counsilman, J.E. (1977). Competitive Swimming Manual: for Coaches and Swimmers. Counsilman Co., Inc., USA.

Dishman, R.K. (1978). Aerobic power, estimation of physical ability and attraction towards physical activity. Research Quarterly 49, 285-292.

Epstein, S. (1973). The self-concept revisited or a theory of a theory. American Psychologist, 28, 405-416.

Eriz, M., \& Zidon, I. (1984). Effects of goal acceptance on the relationship of goal difficulty to performance. Lournal of Aoplied Psychology, 69, 69-78.

Ewart, C.K., Taylor, C.B., Reese, L.B., \& DeBusk, R.F. (1983). Effects of early postmyocardial infarction exercise testing on self-perception and subsequent physical activity. The American Journal of Cardiology 51 , 1076-1080.

Felker, D.W. (1974). Building positive self-concepts. Minneapolis: Burgess.

Ferguson, G.A. (1971). Statistical analysis in Dsychology and education. (3rd edition). New York: McGraw-Hill.

Fox, K.R., Corbin, C.B., \& Couldry, W.H. (1985). Female physical estimation and attraction to physical activity. Journal of Sport Psychology, 7, 125-136.

Gergen, K.J. (1971). The concept of self. New York: Holt.

Gecas, V. (1982). The self-concept. Annual Review of Sociology, 8, 1-33.

Hall, H.K., Weinberg, R.S., \& Jackson, A. (1987). Effects of goal specificity, goal difficulty, and information feedback on endurance performance. Journal of Soort Psychology. 9, 43-54.

Harter, S. (1982). The perceived competence scale for children. Child Development. 53, 87-97.

Heaps, R.A. (1978). Relating physical and psychological fitness: A psychological point of view. Lournal of Sports Medicine and Physical. Eitness. 18, 399-408. 
Horney, K. (1950). Neurosis and human growth. New York: Morton.

Koocher, G.P. (1971). Swimming, competence, and personality change. Lournal of Personality and Social Psychology. 18, 275-278.

Laporte, R.E., \& Nath, R. (1976). Pole of performance goals in prose learning. Journalof Educational Psychology. 68, 260-264.

Larsen, D.W. (1983). Coach inspires more than winning. Seatlle Times. February 14.

Latham, G.P., \& Blades, J.J. (1975). The "practical significance" of Locke's theory of goal setting. Journal of Apolied Psychology. 60, 122-124.

Leonardson, R.R., \& Garguilo, R.M. (1978). Self-perception and physical fitness. Percetual and Motor Skills, 46, 338.

Locke, E.A. (1966). The relationship of intentions to level of performance. Lournal of Apolied Psychology, 50, 60-66.

Locke, E. A. (1968). Tow ard a theory of task motivation incentives. Organizational Behavior and Human Performance. 3. $157-189$.

Locke, E. A. and Byran, J.F. (1969). The directing function of goals in task perfor mance. Organizational Behavior and Human Performance. 4 , $35-42$.

Locke, E.A., Cartlidge, N., \& Knerr, C.S. (1970). Studies of the relationship between satisfaction, goal setting, and performance. Organizational Behavior and Human Performance. 5, 135-158.

Locke, E. A. and Latham, G. (1985). The application of goal setting to sports. Journal of Sport Psychology 7, 205 - 222.

Locke, E.A., Mento, A.J., \& Katcher, B.L. (1978). The interaction of ability and motivation in performance: An exploration of moderators. Personnel Psychology 31, 269-280.

Locke, E. A., Shaw, K. N., Saari, L.M., and Latham, G.P. (1981). Goal-setting and task performance: $1969-1980$. Psvchological Bulletin 90, 125 - 152.

Loeffler, D., \& Fiedler, L. (1979). Woman -- a sense of identity: A counseling intervention to facilitate personal growth in woman. Journal of Counseling Psychology 26, 51-57.

Mace, C.A. (1935). Incentives: Some experimental studies. Industrial Health Research Board (Great Britain), Report no. 72.

Maehr, M.L., Mensing, J., \& Nafzger, J.S. (1962). Concept of self and the reaction of others. Sociometry 25: 353-357. 
Maglischo, E.W. (1982). Swimming Easter Mayfield Publishing, USA.

Miller, J.T., \& McAuley, E. (1987). Effects of a goal-setting training program on basketball free-throw, self-efficacy, and performance. The Sports Psychologist 1 103-113.

Neale, D.C., Sonstroem, R.J., \& Metz, K.F. (1969). Physical fitness, self-esteem, and attitudes towards physical activity. Research Ouarterly 40, 743-749.

Parker, R.S. (1983). Self-image osychodynamics: Rewriting your life scriot. Englewood Cliffs, N.J.: Prentice Hall.

Reiss, E.H. (1986). Physical estimation and attraction scales: Validity in adult women. Master of Science thesis in Physical Education, University of Rhode Island, Kingston.

Rosenberg, M. (1963). The association between self-esteem and anxiety. lournal of Psychiatric Research 1, 135-152.

Rosenberg, M. (1965). Society and the adolescent self image. Princeton, NJ: University Press.

Rosenberg, M. (1979). Conceiving the self New York: Basic Books.

Safrit, M.J., Wood, T.M., \& Dishman, R.K. (1985). The factorial validity of the physical estimation and attraction scales. Journal of Sport Psychology Z, 2.

Scheier, M.A., \& Kraut, R.E. (1979). Increasing educational achievement via self-concept change. Review of Educational Research. 49, 131-150.

Shavelson, R.J., Hubner, J.J., \& Stanton, G.C. (1976). Self-concept: Validation and construct interpretations. Review of Educational Research 46. 407-441.

Sonstroem, R.J. (1974). Attitude testing examining certain psychological correlates of physical activity. Research Quarterly 45, 95-103.

Sonstroem, R.J. (1975). Assessment of attitude toward physical activity and estimation of physical ability: Theoretical and applied considerations. Paper presented at the ACSM Annual Meeting, New Orleans.

Sonstroem, R.J. (1976). The validity of self-perceptions regarding physical and athletic ability. Medicine and Science in Soorts. 8. 126-132.

Sonstroem, R.J. (1978). Physical estimation and attraction scales: Ratinale and research. Medicine and Science in Sports. 10, 97-102.

Sonstroem, R. J. (1984). Exercise and self-esteem: In R.L. Terjung (Ed.) Exercise and sports sciences reviews (Vol. 12), (pp. 123-155). Lexington, MA. 
Sonstroem, R.J., \& Morgan, W.P. (1986). Exercise and Self-Esteem: Rationale and Model. Unpublished manuscript, University of Rhode Island, Department of Physical Education, Health and Recreation, University of Wisconsin-Madison, Sport Psychology Laboratory.

Terborg, J.R. (1976). The motivational components of goal setting. Journal of Apolied Psychology, 61, 613-621.

Tindel, C. (1983). Twenty-six tips for building self-concept. Academic Therapy Seotember, 103-105.

Weinberg, R.S., Bruya, L., Longino, J., \& Jackson, A. (1988). Effect of goal proximity and specificity on endurance performance of primary grade children. Journal of Soort and Exercise Psychology 10, 81-91. 
Appendix A

Parental Consent Form

and

Informed Consent Form 


\section{PARENTAL CONSENT FORM}

I am a graduate student at the University of Rhode Island pursuing a Master's degree in Physical Education/Sport Psychology. The subjects that I have chosen are all male high school swimmers in the State of Rhode Island.

Your son is being asked to answer some questions on his swimming. The purpose of these questions is to learn what people think of themselves in relation to physical activity. This type of information will be helpful in planning future programs for people. As part of my Master's Thesis at the University of Rhode Island, I am studying the thoughts and ideas of high school students.

It should be emphasized that there are ne right or wrong, ne good or bad responses to the questions they are answering. They will answer each item as they really feel about it.

Data will remain strictly confidential. Thier coach will not see these data. They do not have to complete these inventories and they may refuse to do so at any time. Please feel free to ask any questions you may have.

\section{Parental Consent}

Date

The purpose of my son's participation in these procedures has been explained to me. I freely consent to my son's participation. I understand that he is not required to participate and that he may stop participation at any time.

Name

Address

Telephone

KEVIN S. SALISBURY

PARENTS SIGNATURE

291 Tidewater Drive

Warwick, RI 02889

Tel. (401) 738-6979 (H) (401) 434-6776 (W) 


\section{INFORMED CONSENT -- BEHAVIORAL DATA}

You are being asked to answer some questions on the following pages. The purpose of these questions is to learn what people think of themselves in relation to physical activity. This type of information will be helpful in planning future programs for people. As part of my Master's Thesis at the University of Rhode Island, I am studying the thoughts and ideas of high school students.

It should be emphasized that there are no right or wrong, no good or bad responses to the questions you are answering. Please answer each item as you really feel about it.

Data will remain strictly confidential. Your coach will not see these data. You do not have to complete these inventories and you may refuse to do so at any time. Please feel free to ask any questions you may have.

Date

Name

Address

Telephone

\section{Voluntary Consent}

The purpose of my participation in these procedures has been explained to me. I freely consent to participate. I understand that I am not required to participate and that I may stop participation at any time.

KEVIN S. SALISBURY

\section{SIGNAT URE}

291 Tidewater Drive

Warwick, RI 02889

Tel. (401) 738-6979 (H)

(401) 434-6776 (W) 
Appendix B

Rosenberg's (1965) Self-Esteem Scale 
Section I - Use Attached IBM answer sheet only for next 72 items.

The statements below reflect certain attitudes and interests of persons. There are no right or wrong answers. Read each statement and decide the degree to which it applies to you. Indicate your answer by blackening the appropriate space on the separate answer sheet. In some cases you may have difficulty deciding which response is best, but please make some decision and answer every item. Please do not attempt to be consistent in your answers during the test, but respond to each item individually. Even if an item asks about things you have not experienced, answer it as best you can on the basis of what you have heard, seen, or read. Express your agreement or disagreement by filling in the appropriate circle on your answer sheet according to the following:

Strongly Agree Agree A $\mathrm{B}$
Undecided C
Disagree
Strongly Disagree E

You should rarely need to use C (Undecided)

The significance of this research depends upon the degree to which you express your own opinion.

1. I feel that I'm a person of worth, at least on an equal basis with others.

2. I feel that I have a number of good qualities.

3. All in all, I am inclined to feel that I am a failure.

4. I am able to do things as well as most other people.

5. I feel I do not have much to be proud of.

6. I take a positive attitude toward myself.

7. On the whole I am satisfied with myself.

8. I wish I could have more respect for myself.

9. I certainly feel useless at times.

10. At times I think I am no good at all. 
Appendix C

Estimation Scale and Social Desirability Scale 


\section{SECTION II}

11. I always try to be considerate of the feelings of my friends.

12. Most of my friends work harder than I do.

13. I would have made a good accountant.

14. I lack confidence in performing physical activities.

15. Nothing that happens to me makes much difference one way or the other.

16. I of ten take responsibility for looking out for newcomers in a group.

17. I am a good deal stronger than most of my friends.

18. My body is capable of hard exercise.

19. I prefer woodworking to tinkering with a motor.

20. I just don't have the coordination necessary to look like a graceful skier.

21 . In the long run humanity will owe a lot more to the teacher than to the salesperson.

22. I am in better physical condition than most people my age.

23. Vigorous exercise would leave my body tired and sore.

24. I am well equipped to excel at physical activities.

25. Probably I could get into good physical condition faster than most people my age.

26. I have a number of health problems.

27. I am better coordinated than most people I know.

28. I of ten have the feeling that I am doing something evil.

29. I enjoy people who talk a great deal.

30. My body adapts well to exercise.

31. I almost always feel sleepy and lazy.

32. I doubt that I could ever get into good physical condition.

33. Compared to other people I am somewhat clumsy.

34. I can run for longer distances than most people my age. 
35. I have a healthy body.

36. I often doubt my physical abilities.

37. My memory is as good as other peoples.

38. I am not willing to give up my own privacy or pleasure in order to help other people.

39. Most people I know think I have very good physical skills.

40. My body is strong and muscular compared to other people my age.

41. Most of my teachers were helpful.

42. I am seldom ill.

43. My legs have as much spring as those of champion high jumpers.

44. If I wanted to, I could become an excellent tennis player.

45. We ought to let the rest of the world solve their own problems and just look after ourselves.

46. I could do better at long distance hiking than the average person my age.

47. It takes me two days to recuperate from a physical workout.

48. I am quite limber and agile compared to others my age.

49. I really don't have the energy to exercise four times per week.

50. With a fair amount of practice I could maintain a high bowling average.

51. My friends seem to be more physically active than I am.

52. I am stronger than a good many of my friends.

53. It is difficult for me to catch a thrown ball.

54. My life is full of interesting activities.

55. I often question whether life is worthwhile.

56. I am able to make correct decisions on difficult questions.

57. I believe people tell lies anytime it is ti their advantage.

58. I can run faster than most of my friends.

59. Rarely, if ever, has the sight of food made me ill.

60. I find it very difficult to do what is expected of me. 
61. With practice I could become a very good golfer.

62. I exhibit a fair amount of leadership in a sports situation.

63. I am always prepared to do what is expected of me.

64. Even with practice I doubt that I could learn to do a handstand well.

65. I'm a natural athlete.

66. Many things make me feel uneasy.

67. I have a strong throwing arm for baseball or sof tball.

68. It would be very difficult for me to learn to do a back dive.

69. Even with practice I doubt that I could ever learn to do a cartwheel well.

70. I'm not very good at most physical skills.

71. Poor timing handicaps me in certain physical activities.

72. I am a natural leader in sport activities. 
Appendix D

Self-Perceptions of Swimming Skills Inventory 
Name

School

Grade

\section{Swimming Skills Inventory}

The numbered items below represent specific abilities of high school Interscholastic swimmers. Please rate your abilities as compared to the average high school Interscholastic swimmer.

Please circle the number which best represents your own skills and abilities.

1. STARTS

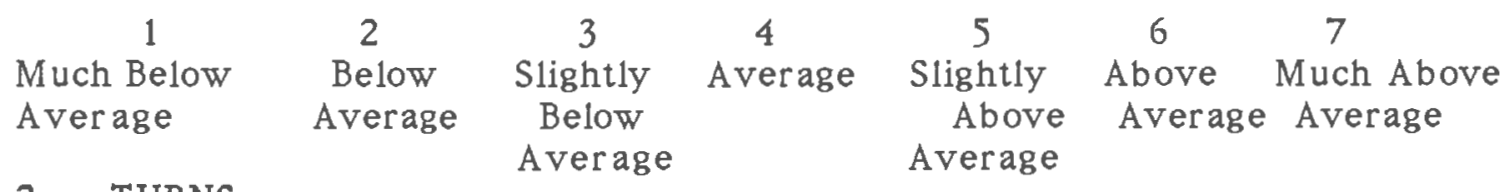

2. TURNS

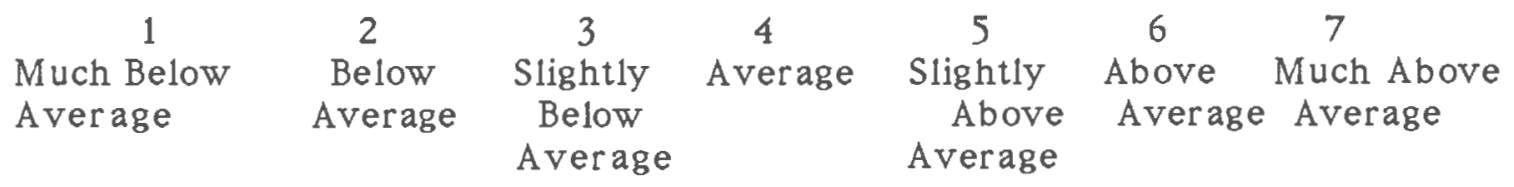

3. ARM STROKE

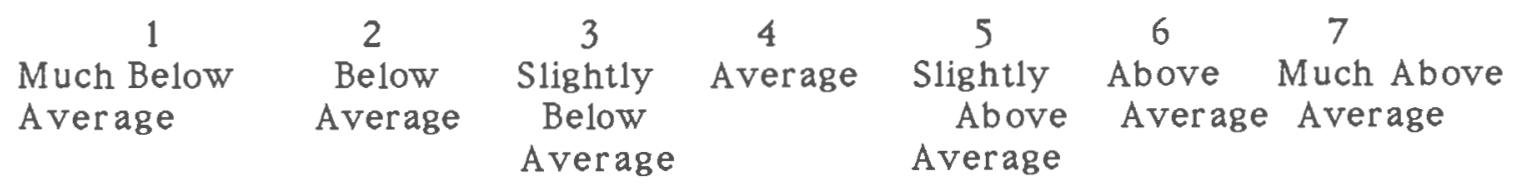

\section{4. $\quad \mathrm{KICK}$ (Legs)}

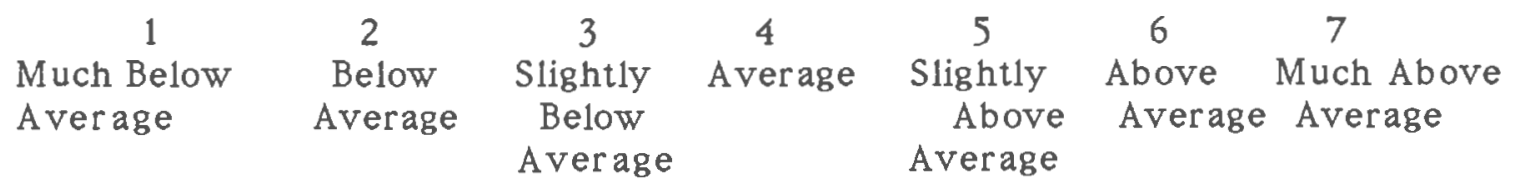

\section{COORDINATION OF STROKES}

\section{$\begin{array}{llllllll}1 & 2 & 3 & 4 & 5 & 6 & 7\end{array}$}

Much Below Below Slightly Average Slightly Above Much Above Average Average Below

Average
Above Average Average

Average 
Appendix E

Personal Performance Goals Inventories 
NAME

SCHOOL

GRADE

PERSONAL PERFORMANCE GOALS INVENTORY

A - Pre

Please answer the following questions according to your competitive high school swimming:

PART I

1. What do you feel is your best event?

2. List your previous best time in this event

3. What goal time do you really wish to reach by January 1,1988 ?

4. How important is this goal to you? (circle one)

$\begin{array}{cccc}\text { Not Very } & \text { Only Sort of } & \text { Pretty } & \text { Very } \\ \text { Important } & \text { Important } & \text { Important } & \text { Important }\end{array}$

\section{PART II}

5. Name your second best event....

6. List your previous best time in this event

7. What goal time do you really wish to reach by January 1,1988 ?

8. How important is this goal to you? (circle one)

$\begin{array}{cccc}\text { Not Very } & \text { Only Sort of } & \text { Pretty } & \text { Very } \\ \text { Important } & \text { Important } & \text { Important } & \text { Important }\end{array}$


NAME

SCHOOL

GRADE

PERSONAL PERFORMANCE GOALS INVENTORY

B-Mid

Please answer the following questions according to your competitive high school swimming. Also, please use the same "best event" and "second best" event when answering these questions.

\section{PART I}

1. What do you feel is your best event?

2. List your best time to date in this event.

3. What goal time do you really wish to reach by State Championships?

4. How important is this goal to you? (circle one)

$\begin{array}{cccc}\text { Not Very } & \text { Only Sort of } & \text { Pretty } & \text { Very } \\ \text { Important } & \text { Important } & \text { Important } & \text { Important }\end{array}$

\section{PART II}

5. Name your second best event....

6. List your best time to date in this event.

7. What goal time do you really wish to reach by State Championships?

8. How important is this goal to you? (circle one)

$\begin{array}{cccc}\text { Not Very } & \text { Only Sort of } & \text { Pretty } & \text { Very } \\ \text { Important } & \text { Important } & \text { Important } & \text { Important }\end{array}$


NAME

SCHOOL

GRADE

PERSONAL PERFORMANCE GOALS INVENTORY

C-Post

Please answer the following questions according to your competitive high school swimming. Also, please use the same "best event" and "second best" event when answering these questions.

PART I

1. What do you feel is your best event?

2. List your best time for the season in this event

PART II

3. Name your second best event....

4. List your best time for the season in this event 
Figure Legend

Eigure 1 Proposed Model for examining exercise and self-esteem interactions. 


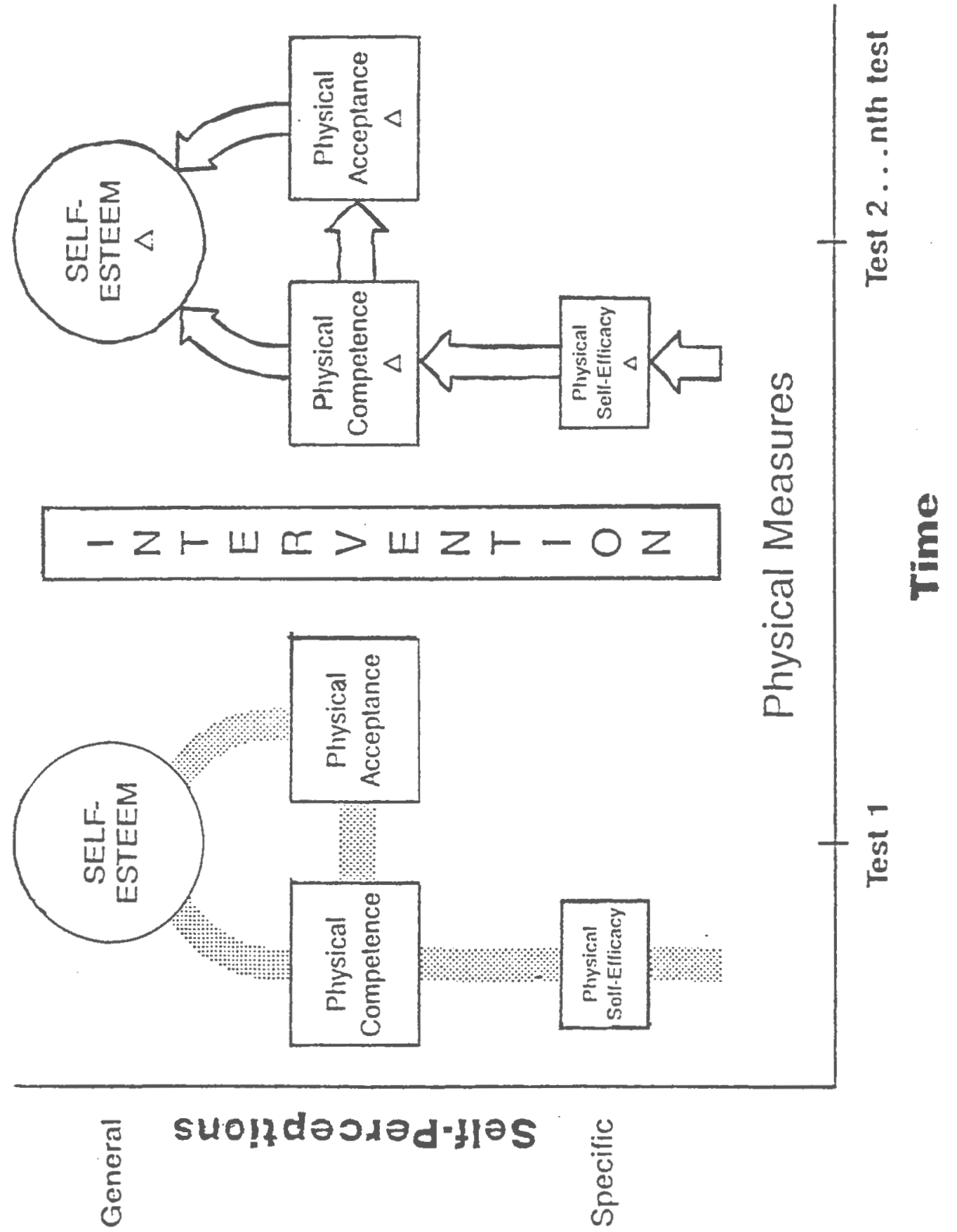




\section{Figure Legend}

Eigure 2. Modified Model for examining the manner in which self-esteem is hypothesized to change 


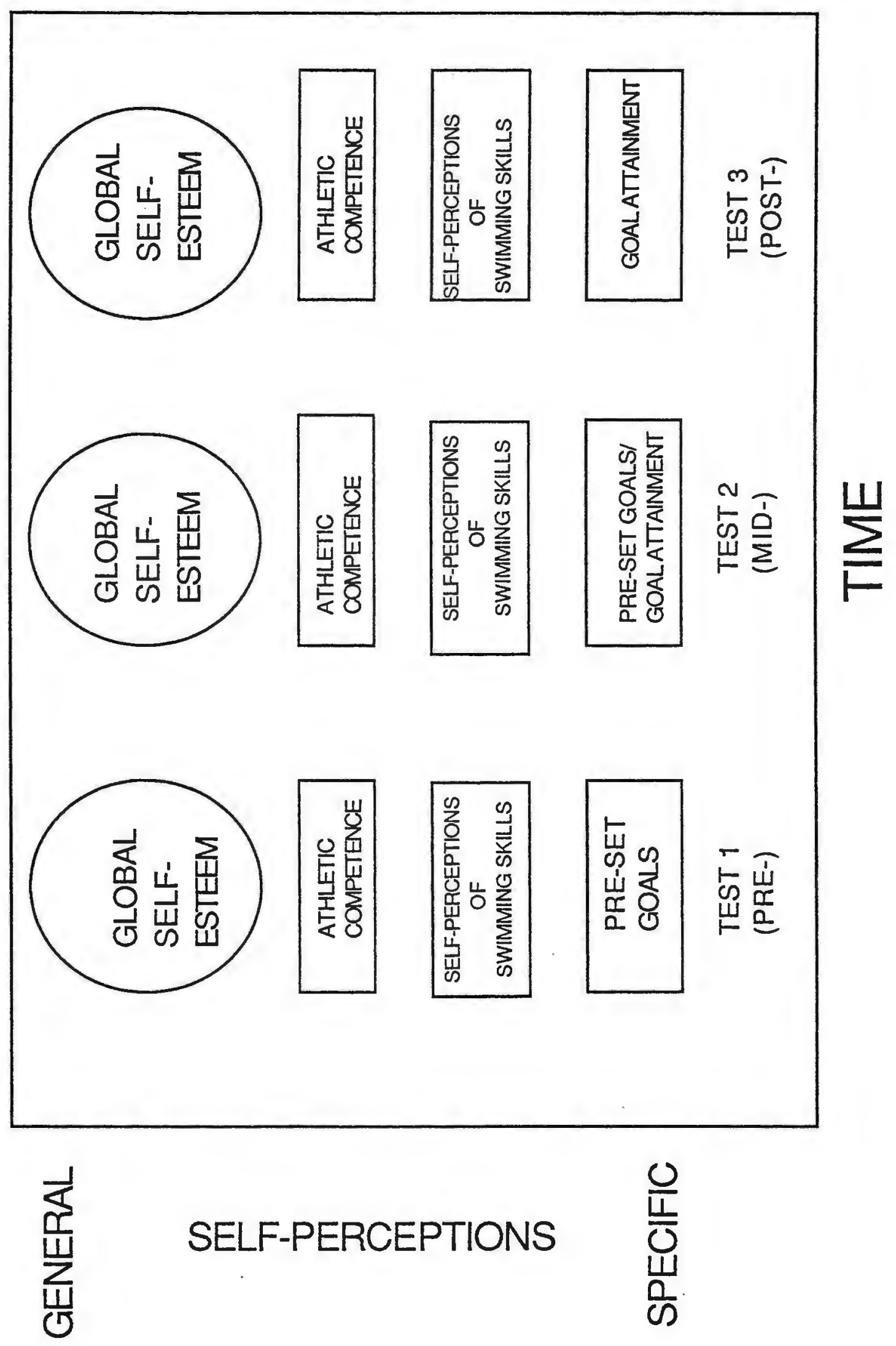

